UNIVERSIDADE DE SÃO PAULO

ESCOLA DE ENFERMAGEM DE RIBEIRÃO PRETO

ISA MENEZES BEZERRA

Assistência de enfermagem ao estomizado intestinal: revisão integrativa de literatura 
ISA MENEZES BEZERRA

\section{Assistência de enfermagem ao estomizado intestinal: revisão integrativa de literatura}

Dissertação apresentada ao Programa de Pós-graduação Área Enfermagem Fundamental do Departamento de Enfermagem Geral e Especializada da Escola de Enfermagem de Ribeirão Preto da Universidade de São Paulo, para obtenção do título de Mestre em Enfermagem Fundamental.

Linha de Pesquisa:

Processo de cuidar do adulto com doenças agudas e crônicodegenerativas

Orientadora: Profa. Dra. Márcia Maria Fontão Zago

\section{Ribeirão Preto}




\section{FICHA CATALOGRÁFICA}

\section{Bezerra, Isa Menezes}

Assistência de Enfermagem ao estomizado intestinal: revisão integrativa de literatura. Ribeirão Preto, 2007.

93 p.:

Dissertação de Mestrado, apresentada à Escola de Enfermagem de Ribeirão Preto/USP. Área de concentração: Enfermagem Fundamental.

Orientador: Zago, Márcia Maria Fontão.

1. Revisão Integrativa. 2. Estomizado Intestinal. 3. Assistência de Enfermagem. 4. Hospital. 


\section{FOLHA DE APROVAÇÃO}

Isa Menezes Bezerra

Assistência de enfermagem ao estomizado intestinal: revisão integrativa de literatura

Dissertação apresentada ao Programa de Pós-graduação Área Enfermagem Fundamental do Departamento de Enfermagem Geral e Especializada da Escola de Enfermagem de Ribeirão Preto da Universidade de São Paulo, para obtenção do título de Mestre em Enfermagem Fundamental.

Linha de Pesquisa: Processo de cuidar do adulto com doenças agudas e crônico-degenerativas

Orientadora: Profa. Dra. Márcia Maria Fontão Zago

Aprovado em :

Banca Examinadora

Profa. Dra. Márcia Maria Fontão Zago

Instituição: Universidade de São Paulo

Assinatura:

Profa. Dra. Maria Helena Pinto

Instituição: Faculdade de Medicina de São José do Rio Preto

Assinatura:

Dra. Helena Megumi Sonobe

Instituição: Universidade de São Paulo

Assinatura: 


\section{DEDICATÓRIA}

Dedico este estudo a todos pacientes portadores de estomas intestinais que enfrentam sua nova condição de vida com perseverança, otimismo $e$ fé. 


\section{AGRADECIMENTOS}

Á Deus por ter me dado força e perseverança desde a iniciativa de cursar a pós-graduação, durante todos esses meses de desafios e agora na finalização do trabalho.

Á minha mãe querida, fonte de sabedoria e garra, que sempre esteve ao meu lado. Agradeço por ter me propiciado a vida e por me dar como herança a sua luz, energia, fé e força de viver.

Aos meus irmãos Joás, Andrea e Flávia por compreender a minha ausência e dar apoio nos meus momentos mais difíceis.

Á querida tia Zulma e prima Cláudia, que mesmo distantes, sempre foram fonte de inspiração e estímulo de luta para fazer a vida sempre melhor.

Á minha querida e grande amiga Helena pela sabedoria, imprescindivel contribuição na minha formação assistencial e científica, pelo seu exemplo e por ter sempre acreditado na minha capacidade. Serei sempre grata.

Á minha orientadora Márcia Zago pela oportunidade de crescimento e aprendizado e pela compreensão nos momentos de dificuldades.

Á todo Hospital das Clínicas de Ribeirão Preto (funcionários e pacientes) pela iniciação na carreira, crescimento e amadurecimento profissional.

Ao Exército Brasileiro pela possibilidade de crescimento como pessoa e estímulo para investir no aprimoramento científico. 


\section{RESUMO}

BEZERRA, I.M. Assistência de Enfermagem ao estomizado intestinal: revisão integrativa de literatura. 2007.87fl. Dissertação (Mestrado) - Escola de Enfermagem de Ribeirão Preto, Universidade de São Paulo, Ribeirão Preto, 2007.

Este estudo consiste de uma revisão integrativa da literatura nacional e internacional sobre a Assistência de Enfermagem Hospitalar ao Estomizado Intestinal, publicada no período de 2002 a 2006. Para realização deste estudo foram utilizadas as fases propostas por Ganong (1987): seleção das hipóteses ou questões para a revisão; estabelecimento de critérios para seleção da amostra; apresentação das características da pesquisa primária; analisar os dados; interpretação dos resultados e apresentação da revisão. Realizou-se a busca on-line dos trabalhos científicos no site Bireme e no sistema Dedalus (USP). Estabelecemos como critérios de inclusão de trabalhos: abordagem da assistência de enfermagem ao estomizado intestinal hospitalizado, realizados com seres humanos, publicados em inglês, espanhol e português e localizados na íntegra; e como critérios de exclusão trabalhos que abordavam outros tipos de estomas (não intestinais), os experimentais com animais, trabalhos direcionados à clientela infantil e trabalhos publicados em outros idiomas que não o inglês, o espanhol ou o português. Obteve-se uma amostra de 22 artigos para análise. Os temas abordados foram categorizados em Cuidados de Enfermagem com 14 (63,6\%) trabalhos científicos; Autocuidado com 4 (18,2\%), e Complicações com 4(18,2\%). A análise dos temas de pesquisa possibilitou identificar a necessidade de realização de pesquisas futuras abordando aspectos específicos como intervenções de enfermagem e estratégias de ensino, em todas as etapas do atendimento hospitalar, assim como a organização e dinâmica de atendimento da equipe de saúde hospitalar. Quanto aos delineamentos das pesquisas, evidenciou-se a necessidade de investimentos nos aspectos metodológicos como uma condição para produção de conhecimento científico que consolida a prática clínica. Descritores: Revisão integrativa. Estomizado Intestinal. Assistência de Enfermagem. Hospital. 


\begin{abstract}
BEZERRA, I.M. Nursing care to the intestinal ostomized: integrative literature review. 2007.87fl. Dissertation (Mastership) - Escola de Enfermagem de Ribeirão Preto, Universidade de São Paulo, Ribeirão Preto, 2007.

The purpose of this dissertation is to present a national and international review about the Hospital Nursing Care to the Intestinal Ostomized from the period of 2002 to 2006. In order to realize this study, the stages proposed by Ganong (1987) were applied: selection of hypothesis or questions to the review, establishment of criteria for the sample selection, presentation of the primary research characteristics, data analysis, interpretation of the results and the review presentation. A research of the scientific works was made on the Bireme website and in the Dedalus (USP) system. The criteria established for the inclusion of the works were: mention of the nursing care approaches to the hospitalized intestinal ostomized, experiments performed on humans' beings, publication of the work in English, Spanish and Portuguese of which the verbatim could be found. And the criteria for exclusion of the works were: works which referred to other types of ostomates (nonintestinal), to the experiments on animals, works aimed to the juvenile public and last, those works published in other languages apart from English, Spanish or Portuguese. Twentytwo sample works were obtained for analysis. The topics were classified in: Nursing Care with $14(63,6 \%)$ scientific works; Self-care with $4(18,2 \%)$ scientific works; and Complications with $4(18,2 \%)$ scientific works. The analysis of the research topics revealed the necessity of future researches on specific aspects, such as nursing interventions and teaching strategies in the different stages of the hospitalar service as well as in the dynamism and organization of the staff's service. Concerning to the delineation of the research, it became evident that there is also the necessity of investment in methodological aspects as a main condition to the acquisition of scientific knowledge to consolidate the clinic practice.

Describers: Integrative Review, Intestinal Ostomized, Hospitalar Nursing Care.
\end{abstract}




\section{RESUMEN}

BEZERRA, I.M. Asistencia de enfermería al ostomizado intestinal: revisión integradora de literatura.2007.87fl Dissertácion (Maestría) - Escola de Enfermagem de Ribeirão Preto, Universidade de São Paulo, Ribeirão Preto, 2007.

Es una revisón integradora de literatura nacional y internacional sobre la Asistencia de Enfermaría Hospitalaria al ostomizado intestinal, en el período de 2002 a 2006. Para la realización del estudio fueron utilizadas las fases propuestas por Ganong (1987): seleción de las hipóteses o questiones para la revisión, establecimiento de critérios para la seleción da muestra, presentácion de las características de la investigación primária; análise de los datos, interpretación de los resultados y presentación de la revisión. Realizóse la busqueda on-line de los trabajos científicos en el site Bireme y en el sistema Dedalus (USP). Estabelecióse los criterios de inclusión de trabajos: abordaje de la asistencia de enfermería al ostomizado intestinal hospitalizado, realizados con seres humanos, publicados en inglés, español y portugués; localizados na íntegra; los criterios de exclusión fueron trabajos que abordaban otros tipos de ostomías (no intestinales), los experimentales con animales, trabajos direccionados a clientela infantil y trabajos publicados em otros idiomas que no el inglês, el español o el português. Obtuvese una muestra de 22 trabajos para análise. Los temas abordados fueron categorizados en Cuidados de Enfermería con 14 (63,6\%) trabajos científicos, Autocuidado con 4 (18,2\%) y Complicaciones con 4 (18,2\%). El análise de los temas posibilitó identificar necesidad de investigación sobre aspectos específicos como intervenciones de enfermería y estratégias de enseñanza, en todas las etapas del atendimiento hospitalaria, así como la organización y dinámica de los profesionales de salud hospitalaria. Cuanto al delineamiento de investigación evidencióse la necesidad de inversión en los aspectos metodológicos como una condición para produción de conocimiento científico que consolida la práctica clínica.

Descriptores: Revisión integradora. Ostomizado intestinal. Asistencia de Enfermería. Hospital. 


\section{SUMÁRIO}

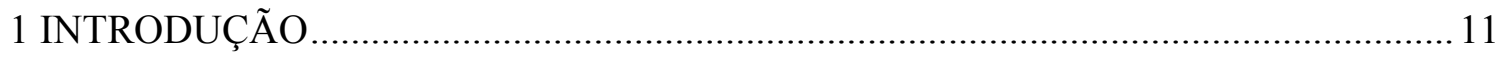

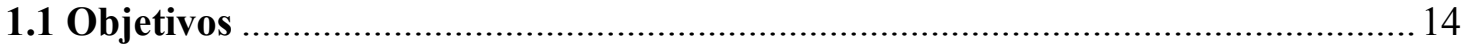

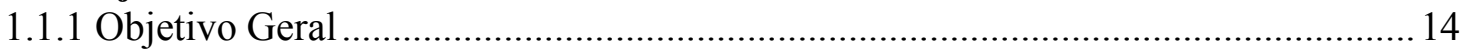

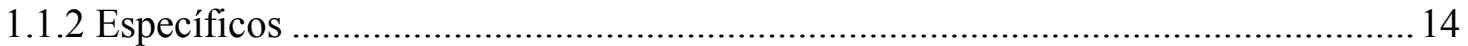

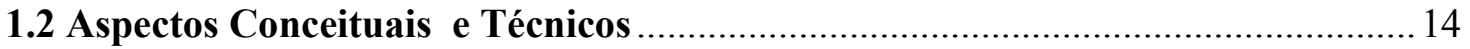

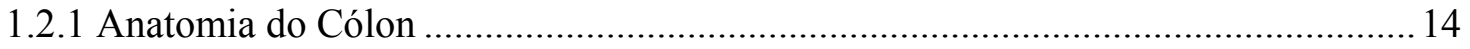

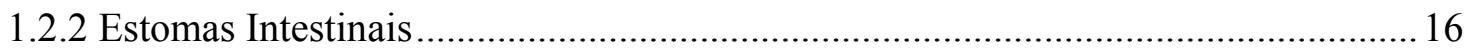

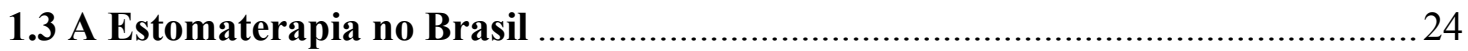

1.4 A Assistência de Enfermagem ao Estomizado Intestinal......................................29

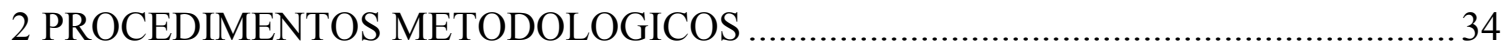

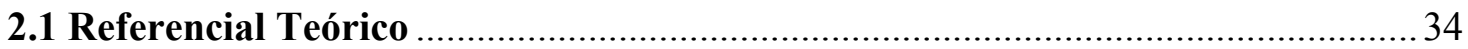

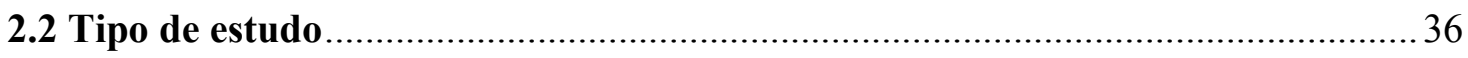

2.3 Procedimento para Seleção dos Artigos Científicos............................................. 40

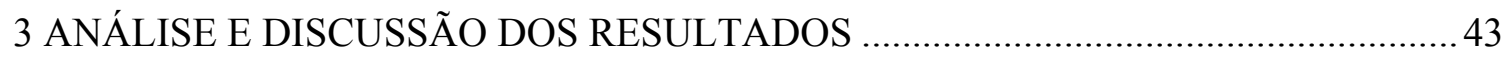

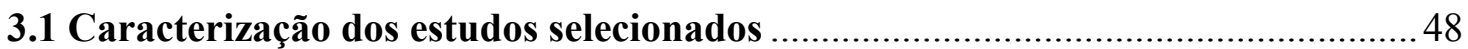

3.2 Assistência de enfermagem hospitalar aos estomizados intestinais...................... 58

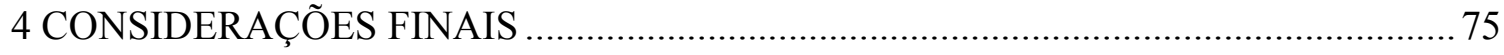

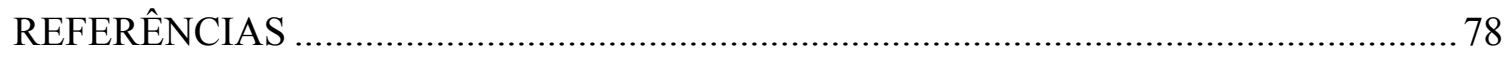

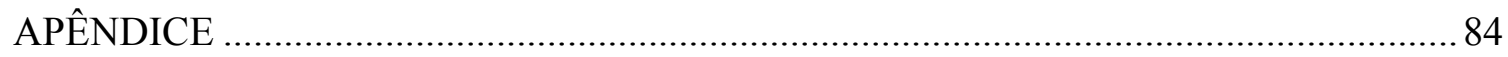

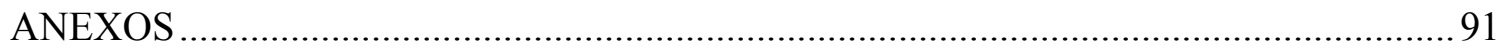

Instrumento para Coleta de Dados Bibliográficos ..................................................... 91 


\section{INTRODUÇÃO}

O período de trabalho em uma clínica cirúrgica de um hospital público, como auxiliar de enfermagem, propiciou o primeiro contato com os pacientes portadores de estomas intestinais. A partir de então pude refletir sobre a problemática dos estomizados, principalmente no que diz respeito à necessidade de assistência de enfermagem especializada para esta clientela. Ao cuidar dos pacientes e seus familiares pude perceber as necessidades do indivíduo como um todo, principalmente no que tange à autonomia do paciente, auto-imagem, qualidade de vida, papel social do indivíduo e apoio familiar.

Em tempo, ingressei no curso de graduação em enfermagem, durante o qual realizei trabalhos de pesquisa (Programa de Iniciação Científica) que contribuíram para o aprofundamento de meus conhecimentos na área. Ao desenvolver trabalhos compreendi a importância da pesquisa científica para fornecer base sólida ao cuidado de enfermagem aos portadores de estomia intestinal. Com o objetivo de conhecer a dinâmica de organização de atendimento ao estomizado intestinal e ampliar a compreensão da vida do estomizado no domicílio, realizei um estágio voluntário no Programa de Ostomizados do SUS, na cidade de Ribeirão Preto. Neste estágio constatei as inúmeras dificuldades enfrentadas pelo paciente na adaptação a sua nova condição, principalmente em relação aos cuidados com o estoma, assim como o enfrentamento da doença, o estigma social por ser portador de câncer e ser estomizado, e o convívio em grupo e família, que são fontes de preocupação deste paciente.

Desta forma, a experiência profissional e a aproximação com os pacientes, aliados aos conhecimentos científicos adquiridos na universidade sedimentaram a minha motivação para pesquisar sobre a assistência de enfermagem ao estomizado intestinal. 
Atualmente, temos como uma das áreas de especialização para o enfermeiro a Enfermagem em Estomaterapia, com cursos predominantemente na região sudeste e com profissionais especializados em várias regiões do país. Entretanto, ainda não temos na grande maioria das instituições hospitalares enfermeiros-estomaterapêutas, que atuem e desenvolvam a sistematização da assistência de enfermagem especializada a essa clientela.

O cuidado de enfermagem aos estomizados não possui uma sistematização desenvolvida como protocolo na rede hospitalar. Ainda, a responsabilidade deste planejamento fica atrelada aos esforços individuais de enfermeiros generalistas. Desta maneira, a grande maioria dos pacientes recebe orientações e cuidados especializados somente quando entram em contato com o Programa dos Estomizados, mantido pelo Sistema Único de Saúde.

No entanto, verificamos durante a prática clínica que o paciente, ao chegar ao Programa dos Estomizados, no período pós-operatório, com muitos dias após a alta hospitalar, já trilhou um caminho longo de sofrimento por inabilidade no cuidado com o estoma, falta de equipamentos coletores e outras situações constrangedoras, que intensificam sua angústia e experiência negativa em relação a sua nova condição.

Temos algumas iniciativas das empresas, fabricantes de equipamentos coletores e produtos para estomizados que contratam profissionais para realizar atendimento domiciliar aos pacientes. Porém, estes profissionais não suprem a demanda de novos pacientes a cada dia. 
Neste contexto, defini o interesse em estudar a assistência de enfermagem aos colostomizados na pós-graduação, nível mestrado, e realizar uma revisão integrativa de literatura para contextualização e fortalecimento do conhecimento sobre a temática.

Acreditamos que há grande necessidade de pesquisas para fornecer base científica às ações de enfermagem e que a síntese do conhecimento produzido até o momento será de grande valia para os futuros pesquisadores desta área e fornecerá subsídios para os profissionais que assistem os pacientes com estomias intestinais.

A revisão de literatura tem como um de seus objetivos a orientação sobre o conhecimento produzido, em uma área de investigação, para identificar e confirmar a pesquisa que pode trazer melhor contribuição científica à temática. Desta forma, auxilia na consolidação de conhecimentos científicos significativos para a profissão ${ }^{1}$.

É necessário investigar, explicitar o corpo de conhecimento científico produzido, assim como, identificar as prioridades de pesquisa para fornecer respaldo e direcionamento científico às ações de enfermagem.

O desenvolvimento e a utilização de conhecimentos científicos são essenciais para a melhoria constante dos cuidados de enfermagem. A fundamentação das decisões e ações de enfermagem fortalece a identidade da enfermagem como profissão e ciência. 


\subsection{Objetivos}

Neste estudo realizamos uma revisão integrativa de literatura sobre a assistência de enfermagem hospitalar aos estomizados intestinais, com os objetivos abaixo discriminados.

\subsubsection{Objetivo Geral}

* Sintetizar o conhecimento produzido e publicado na literatura nacional e internacional sobre a Assistência de Enfermagem Hospitalar aos Estomizados Intestinais, no período de 2002 a 2006.

\subsubsection{Específicos}

- Caracterizar os estudos nacionais e internacionais sobre a assistência aos estomizados intestinais, no âmbito hospitalar;

- Identificar o delineamento dos estudos realizados;

- Categorizar e analisar as temáticas estudadas e as intervenções propostas pelos autores dos estudos;

- Identificar as prioridades de pesquisa na assistência dos estomizados intestinais.

\subsection{Aspectos Conceituais e Técnicos}

\subsubsection{Anatomia do Cólon}

Para compreender a fisiopatologia e as modificações que ocorrem nos pacientes com estomias intestinais, abordaremos especificamente os aspectos anatômicos e cirúrgicos da porção gastrintestinal. 
O cólon é embriologicamente dividido em duas partes: o cólon transverso e a porção proximal a ele, que são derivados do intestino médio, e a metade distal do cólon, derivada do intestino posterior ${ }^{2}$.

Formado pelo ceco, ascendente, flexura hepática, transverso, flexura esplênica, descendente e sigmóide, o cólon difere do intestino delgado por várias características anatômicas:

- disposição mais periférica na cavidade abdominal, semelhante a uma moldura;

- menor extensão; seu comprimento total corresponde a 1/4 do intestino delgado, ou seja, cerca de $150 \mathrm{~cm}$;

- maior diâmetro, mas variável, mede cerca de 7,5 cm no ceco e 2,5 no sigmóide;

- presença de haustrações, pregas semilunares, apêndices epiplóides e tenias.

As principais funções do cólon são: absorver água e eletrólitos presentes no quimo que entra pelo íleo e estocar o material fecal, determinando a freqüência, a consistência e o volume das evacuações. Durante 24 horas, o cólon de uma pessoa sadia absorve cerca de $1.300 \mathrm{ml}$ dos $1.500 \mathrm{ml}$ de quimo líquido, $\mathrm{Na}$ e $\mathrm{K}$. Para que todos os processos digestivos ocorram, é necessário que o material fecal seja impulsionado lentamente ${ }^{2}$.

A motilidade colônica adequada é controlada pelo sistema nervoso, intrínseco e extrínseco, e pela ação de vários hormônios que também agem na estimulação intestinal (gastrina, colecistocinina, substância P, encefalinas) ou na inibição (glucagon, peptídeo vasoativo intestinal e secretina). A agitação e mistura freqüente permitem que todo o material seja exposto uniformemente à superfície mucosa para haver absorção ideal. 
Completado o processo, o conteúdo colônico a ser exonerado fica armazenado no sigmóide e no reto, sob ação do controle voluntário da defecação ${ }^{2 .}$

O tempo de trânsito orocecal é de aproximadamente 6 horas e o trânsito através de todo intestino grosso leva em média 36 horas $^{2}$.

A atividade motora intestinal é constituída de movimentos intestinais nãopropulsivos (movimentos haustrais e movimentos segmentares) e propulsivos (propulsões haustrais e peristalse ou movimentos em massa) ${ }^{2}$.

\subsubsection{Estomas Intestinais}

O vocábulo "estoma" tem origem grega a partir do étimo "stóma"; exprime a idéia de "boca" e tem como sinônimo "estômato".

Os estomas intestinais são feitos em alças com mobilidade e comprimento adequados, que facilitam a exteriorização através da parede abdominal. O sigmóide e o transverso são habitualmente móveis, o ascendente e o descendente fixos e o ceco pode ser fixo, parcialmente móvel ou completamente livre. Dessa maneira os segmentos mais apropriados são o íleo e os cólons transverso e sigmóide. Os segmentos fixos do cólon poderão ser exteriorizados quando devidamente liberados ${ }^{3}$. Em função da porção intestinal onde a estomia é confeccionada, nomes específicos são dados como ileoestoma (porção do intestino delgado) e colostomia (porção do intestino grosso).

Alguns aspectos gerais importantes devem ser considerados na indicação dos estomas intestinais e estão relacionados:

* ao paciente: idade, obesidade, condições gerais e locais, aspectos intelectuais e psíquicos, tipo da doença (extensão, gravidade e etc.). 
* ao procedimento cirúrgico: emergência ou eletivo

*à confecção do estoma - técnica cirúrgica

* à localização: na parede abdominal ou no períneo

* à temporalidade da condição: temporária ou definitiva

* ao tipo de estomia confeccionada: terminal, em alça ou bocas separadas

* à finalidade da indicação da estomia: descompressão, proteção e etc.

* ao segmento intestinal envolvido: ileestoma, colostomia ou cecestoma

* à equipe cirúrgica: habilidade e familiaridade com as técnicas operatórias

*ao enfermeiro e equipe de enfermagem: capacidade técnica-científica para realizar os cuidados específicos e especializados

O enfermeiro deve ter capacidade e habilidade para realizar a técnica de demarcação de estoma e o planejamento da assistência de enfermagem em todo o perioperátorio. O planejamento da assistência tem como objetivo o alcance da recuperação e reabilitação biopsicossocial do estomizado, com o ensino para o autocuidado.

Ileostomias

As ileostomias são principalmente indicadas em pacientes portadores de doenças inflamatórias intestinais (retocolite ulcerativa inespecífica, diverticulite e doença de Cröhn), polipose múltipla familiar, ileostomias protetoras de anastomoses de íleo ou colorretais e obstrução e/ou perfuração por neoplasia de cólon ${ }^{3}$.

O conteúdo ileal líquido ou semilíquido é alcalino e rico em enzimas proteolíticas, e, portanto pode causar lesões e dermatites graves quando em contato com a pele. Nesse 
sentido a ileostomia deve ser confeccionada com eversão da mucosa e protrusão da alça, com saliência de cerca de 3 a 6 cm da borda cutânea, após a eversão. Assegura-se dessa forma que a secreção ileal seja drenada diretamente dentro da bolsa coletora, prevenindo contato e lesões de pele ${ }^{3}$.

As ileostomias podem ser de caráter temporário ou definitivo e tecnicamente podem ser confeccionas como ileostomias terminais, em alça ou em bocas separadas.

Cecostomias

São pouco realizadas, dando-se preferência as transversostomias. São indicadas em pacientes com obstrução do cólon esquerdo e transverso, em pacientes obesos (onde é difícil exteriorizar o transverso), e naqueles com pseudo-oclusão aguda do cólon e perfurações ou volvo do ceco $^{3}$.

Nas cecostomias são utilizadas sondas como a do tipo Foley ou Malecot dentro do ceco, que são fixadas por uma sutura em bolsa que comprime a parede do ceco contra a sonda. Assim, a cecostomias é fechada e a sonda exteriorizada por contra abertura na fossa ilíaca direita e não pela incisão de acesso ao ceco ${ }^{3}$.

Colostomias

As colostomias permanentes são indicadas na ocorrência de tumores que acometem o canal anal, 1/3 inferior do reto e retites estenosantes (infecções, radioterapia, doença de Cröhn e fístulas complexas). Já as colostomias temporárias são indicadas em situações emergenciais devido às obstruções intestinais por tumores, volvo do sigmóide, doença diverticular; perfurações por isquemia, traumas, deiscência de anastomoses e doença de Cröhn; infecções por fístulas complexas e síndrome de Fournier; diferentes afecções que 
demandam anastomoses em reto baixo (colostomias para proteção de anastomose); concomitante ou previamente às cirurgias de fístulas anorretais complexas ou em esfincteroplastias ${ }^{4}$.

As colostomias podem ser de caráter temporário ou permanente, tipo de estomia terminal ou em alça, confecção com bocas justapostas ou separadas, com localização abdominal ou perineal. Nas colostomias em alça, utiliza-se um suporte (pino) de sustentação que passa pelo mesocolo da alça exteriorizada e apóia-se na pele e no tecido subcutâneo, permanecendo por cerca de uma semana, quando ocorre a maturação da estomia e é retirado. A razão desse pino é manter o cólon na posição e evitar o desabamento da colostomia nos primeiros dias após a sua construção ${ }^{3}$. Este pino é confeccionado por material plástico como sonda tipo Levine ou mesmo com aço inoxidável.

A colostomia perineal é uma opção nas ressecções do reto e do ânus e é denominada colostomia perineal continente, pois a alça intestinal remanescente é posicionada e fixada na ferida do períneo, à semelhança de um neo-ânus. Isso permite ao paciente fazer lavagens periódicas (irrigação intestinal), com freqüência a cada 24 horas ou com maiores intervalos, que possibilita a eliminação de fezes e manter-se limpo, com continência e sem a necessidade de equipamentos coletores ${ }^{3}$. É denominada reeducação intestinal e é de responsabilidade do enfermeiro estoma-terapeuta, que define o esquema, faz o ensino de autocuidado e o seguimento deste paciente.

Complicações dos Estomas Intestinais

Complicações cirúrgicas precoces e tardias podem ocorrer nos estomizados, no período pós-operatório, relacionados aos aspectos físicos gerais do paciente e ao local 
cirúrgico. Abordaremos especificamente os fatores cirúrgicos relacionados às complicações precoces nas estomias.

As complicações precoces são classificadas em isquemia parcial ou necrose do cólon; hemorragias; desabamentos (retração do estoma); infecção (abscesso, celulite) periestomal; edema da mucosa e dermatites. As complicações tardias são classificadas em estenose; obstrução e perfuração; prolapso da colostomia; hérnia paracolostômica; fístulas íleo ou colocutâneas e raras (evisceração e neoplasia) ${ }^{3}$.

\section{Escolha do Local da Estomia}

A seleção do local do estoma no período pré-operatório tem fundamental importância e deve ser enfatizada, sendo possível sua realização mesmo em pacientes a serem operados em situações de emergência quando o local adequado para o estoma pode ser demarcado. Nas ocasiões em que a demarcação pré-operatória não pode ser realizada vale a regra que, para doentes próximos ao peso ideal, o estoma deve ser posicionado através do reto abdominal poucos centímetros abaixo da cicatriz umbilical sobre a linha que une esta à espinha ilíaca ântero-superior ${ }^{5}$.

Em doentes obesos, a posição do estoma deve ser deslocada alguns centímetros cranialmente a fim de situar o estoma sobre o "avental” constituído pelo tecido subcutâneo. Nesses pacientes, o estoma pode ser posicionado no nível da cicatriz umbilical ou acima dela $^{5}$.

A cicatriz umbilical, pregas da pele, outras cicatrizes e proeminências ósseas devem ser mantidas a pelo menos $5 \mathrm{~cm}$ do local do estoma, para não prejudicar a aplicação da 
bolsa coletora. O local escolhido também deve ser facilmente visualizado pelo paciente, o que possibilita o manuseio da derivação com conforto e segurança ${ }^{5}$.

As ileestomas são, geralmente, posicionadas no quadrante abdominal inferior direito, as colostomias do sigmóide, no inferior esquerdo, e as colostomias do transverso, no quadrante abdominal superior direito ${ }^{5}$.

Equipamentos para Estomias Intestinais

A diversidade de produtos ofertada às pessoas estomizadas, no mercado comercial, torna necessário ao enfermeiro o conhecimento aprofundado das características dos equipamentos, bem como do estoma e dos hábitos de vida do paciente, para indicar o equipamento para o paciente. Devem ser avaliados aspectos que tragam benefícios como conforto, segurança e praticidade, além da proteção da pele, adaptação adequada e permanência na região periestoma ${ }^{6}$.

Vários equipamentos podem ser utilizados durante o tempo em que a pessoa permanece com o estoma e há necessidade de avaliação periódica, de acordo com características específicas apresentadas pelo paciente como variação de peso, modificações do próprio estoma, adaptação e estilo de vida e características da pele periestoma.

Dentre os equipamentos para coleta fecal temos as bolsas com sistemas drenável ou fechado; de uma ou duas peças; bolsas opacas ou transparentes e ainda com resina recortável ou pré-cortada.

A base de resina (anteriormente denominada de placa) que adere à pele pode ser plana ou convexa, com barreira protetora de pele e/ou adesivo microporoso ou de outra natureza. As bases planas são indicadas para estomas com protrusão que permita adaptação 
ao estoma, enquanto as bases convexas são indicadas para estomas planos, sem protrusão ou retraídos ${ }^{6}$.

No período pós-operatório imediato e mediato indica-se o uso de bolsas transparentes e de peça única para facilitar a visualização e avaliação do estoma e do efluente, para evitar a manipulação do abdome do paciente e minimizar a dor.

Já no pós-operatório tardio o estomizado pode escolher, com auxílio profissional do enfermeiro, o equipamento que permita a sua adaptação e retorno às atividades cotidianas e que lhe dê segurança.

Protetores cutâneos são indicados para facilitar a colocação do equipamento ao estoma. São materiais constituídos por hidrocolóides, variando entre gelatina, pectina e carboximetil-celulose sódica que formam a resina sintética; karaya, que é uma resina natural e resina alcoólica. Podem ser parte integrante das bases dos equipamentos ou podem ser isolados e tem apresentação em forma de base, disco, pasta, pó, spray, cremes e películas (lenços umedecidos e bastão) ${ }^{6}$.

Em alguns casos faz-se necessário o uso de mais de um protetor cutâneo ou a troca de protetores para adequação à pele e ao estoma do paciente para prevenir lesões.

Para os pacientes que possuem estomias definitivas (colostomia, sigmoidestoma ou colostomia perineal) é possível assegurar a continência intestinal, por meio de um procedimento denominado irrigação intestinal.

Para os pacientes que possuem outros tipos de estomias pode ser indicado o obturador. 
O sistema de irrigação é composto por uma bolsa plástica com capacidade de 2 litros, a abertura superior é destinada à entrada de água, e a extensão inferior à drenagem de água, com regulador de velocidade de infusão ${ }^{6}$.

Existem vários modelos de irrigador intestinal, de diferentes fabricantes, com apresentação de mostrador de fluxo ou sensor que indica a temperatura da água. A parte distal da extensão apresenta um cone de material plástico e flexível que se adapta aos diferentes tamanhos de estoma, e impede o refluxo de água e a perfuração acidental da alça intestinal. Uma bolsa com duas aberturas (manga) completas o sistema, a abertura superior pela qual se introduz o cone no estoma e outra inferior para a drenagem das fezes até o vaso sanitário. Pode-se utilizar mini-bolsa ou "stoma cap" após a irrigação, com intuito de proteção do estoma (traumas), para pequena umidade e controle de odor ${ }^{6}$.

O oclusor ou obturador é uma prótese flexível de espuma, com revestimento de material hidrossolúvel ao contato com a mucosa intestinal, que possibilita o controle de eliminações fecais e diminui ruídos pela emissão de gases. Seu uso pode ser isolado, no caso dos ileostomizados; ou associado à irrigação, no caso dos colostomizados.

Complementos aos equipamentos podem ser indicados; tratam-se dos cintos de elásticos, discos convexos, lingerie de bolsa, clipe de fechamento e solventes para remoção de resíduos de resina na pele, filtros de carvão, loções limpadoras e desodorizantes líquidos e em pó ${ }^{6}$.

Existe uma vasta variedade de equipamentos e complementos, que indicados com propriedade para cada pessoa, melhora a qualidade de vida do paciente. Entretanto, enfatizamos que a avaliação do profissional enfermeiro ou estoma-terapeuta é o diferencial 
para que o paciente tenha acesso a esses recursos e alcance a adaptação e reabilitação, adequada ao estilo de vida de cada um.

Para a enfermagem o conhecimento específico e especializado é imprescindível para o planejamento da assistência, tanto quantitativo como qualitativo, pois envolvem a previsão e a provisão de recursos humanos, materiais e físicos. A assistência de enfermagem com base em conhecimento científico possibilita a sistematização do cuidados aos estomizados intestinais, de forma otimizada e com qualidade, no âmbito hospitalar.

\subsection{A Estomaterapia no Brasil}

A evolução da Estomaterapia no Brasil, como especialidade para o enfermeiro, está relacionada com o desenvolvimento das técnicas cirúrgicas, ao longo da história.

As primeiras cirurgias abdominais, conhecidas através dos escritos de Aurelianus Caelius, ocorreram em torno do ano 300 a.C. e foram efetuadas por Praxágoras que operava e manipulava o íleo, em casos de trauma abdominal ${ }^{5}$.

Alex Litré é considerado o "pai da colostomia", apesar de não confeccioná-la, a idealizou em 1710, ao realizar a autópsia em um recém-nascido com malformação retal e descobriu que poderia exteriorizar as alças intestinais através da parede abdominal ${ }^{5}$.

A primeira ileestoma de que se tem registro foi confeccionada em 1879 , mais de cem anos após as colostomias, por Baum, cirurgião alemão. Foi confeccionada como uma derivação provisória em paciente com câncer obstrutivo no cólon ascendente, que faleceu após o seu fechamento, em função de deiscência de anastomose ileocolônica ${ }^{5}$. 
A partir daí, mesmo sendo reduzida a freqüência de operações para confeccionar estomias, diversas técnicas foram aperfeiçoadas para exteriorizar as alças intestinais, principalmente o íleo, com o objetivo de facilitar o manejo do estoma pelo paciente, após a alta hospitalar. Ainda assim, essas operações eram acompanhadas por altos índices de mortalidade e morbidade.

Esta situação prevaleceu até 1930, quando McBurney exteriorizou a ileestoma separadamente da incisão principal, abrindo espaço para criação de novas técnicas ${ }^{5}$.

A década de 1950 constituiu um marco no desenvolvimento da área de estomias. Surge a proposta cirúrgica de eversão total da mucosa ileal, quase que simultaneamente por Turnbull, em Cleveland, nos estados Unidos e por Broka, em Londres, na Inglaterra, utilizada até os dias de hoje, que melhorou a qualidade de vida do ileostomizado. Caracterizam-se também por grande número de publicações na área médica sobre técnicas cirúrgicas, cuidados pós-operatórios, balanços hídrico e eletrolítico, manuseio de bolsas e controle de odor, além de aspectos como sexualidade, gravidez e reabilitação 5 .

No campo dos equipamentos coletores, o maior avanço foi a descoberta do pó de Karaya por Turnbull, em 1952. A Karaya, goma com poder absorvente extraída de uma árvore existente na Índia, foi utilizada para produção de uma bolsa com um anel da referida goma, que pudesse ser utilizada na fase pós-operatória. Esta foi a primeira barreira protetora de pele periestoma 5 .

A primeira publicação referente ao cuidado dos estomizados foi feita em 1930 por Dubois, no American Journal of Nursing, onde o autor considerou o estoma como deficiência e descreveu alguns aspectos individuais e ambientais, utilizando como 
parâmetros a alimentação, a localização do estoma como critérios para a indicação dos procedimentos cirúrgicos e cuidados a serem realizados.

Desse modo, até os anos 50, a enfermagem utilizava mais o método empírico para o cuidado, com escassas publicações científicas na área ${ }^{5}$.

Em 1958, Norma Gill, paciente ileostomizada e muito interessada em ajudar outros estomizados, foi convidada pelo seu médico Rupert Turnbull para atuar na Cleveland Clinic Foundation como "técnica em estomia". Nascia assim a estomaterapia e Norma Gill foi considerada a primeira estomaterapeuta ${ }^{5}$.

Em 1968, ainda por sugestão de Turnbull e tendo à frente Norma Gill, constitui-se a primeira organização de estoma-terapeutas através da American Association of Enterestomal Therapistis (AAET) que em 1970 passou a chamar-se North American Association of Enterestomal Therapistis (NAAET) e em 1971, International Association for Enterostomal Therapy (IAET), atualmente Wound, Ostomy and Continence Nursing Society - WOCNS

Com o desenvolvimento de novos cursos, são feitos investimentos em pesquisas de novos produtos e o aumento do interesse pela especialidade passou-se à organização de Conferências Anuais e Congressos, nos quais passou-se a discutir não só aspectos referentes à anestesia e à evolução da cirurgia, como também aos dispositivos coletores e protetores de pele e os cuidados especializados para essa clientela.

A Estomaterapia é uma especialidade estabelecida para enfermagem pelo World Council of Enterostomal Therapists (WCET), a partir de 1980, e o especialista é denominado estoma-terapeuta $(\mathrm{ET})^{5}$. 
A Estomaterapia no Brasil oficialmente iniciou-se com a implantação do Curso de Especialização em Enfermagem em Estomaterapia, na Escola de Enfermagem da Universidade de São Paulo ${ }^{5}$. Atualmente estão sendo realizados cursos de especialização em Taubaté (SP), Juiz de Fora (MG), Fortaleza (CE), Campinas (SP) e Belo Horizonte (MG), Curitiba (PR) e Recife (PE). Estima-se que no Brasil são cerca de 500 enfermeirosestoma-terapeutas.

Um outro feito que poderia ser imputado em grande parte à implantação dos cursos de especialização e que também constituiu um marco na história da estomaterapia brasileira, foi a fundação da Sociedade Brasileira de Estomaterapia (SOBEST), em dezembro de 1992, denominada Sociedade Brasileira de Estomaterapia: estomas, feridas e incontinências, a partir de 1997.

O estatuto da Sociedade Brasileira de Estomaterapia (SOBEST), oficializado em maio de 1993, define Enfermagem em Estomaterapia como sendo ${ }^{5}$ :

\footnotetext{
...uma área especializada da prática de enfermagem voltada para o cuidado dos indivíduos portadores de estomas, feridas drenantes, fístulas, incontinências esfincterianas (anal e urinária) e trauma tissular atual ou potencial, desde a fase pré-operatória, quando indicado, até o período pós-operatório imediato, mediato e tardio ou ambulatorial, objetivando a efetividade do processo de reabilitação.
}

O ET é, portanto, aquele com conhecimento científico, treinamento e habilidade para o cuidado de qualquer tipo de estomizado e de portadores de fístulas, feridas agudas e crônicas e incontinências anal e urinária. 
Ao ET foram estabelecidas as seguintes funções, que delimitam a amplitude de sua atuação:

- função assistencial e de apoio especializado: que engloba as atividades de assistência individualizada nas fases pré e pós-operatória imediata, mediata e tardia, voltadas à reabilitação e a qualidade de vida do indivíduo, enfatizando o autocuidado e a integração junto à família e à equipe interdisciplinar. Envolve não só o cuidar de problemas reais como potenciais, implicando intervenções preventivas, curativas e de reabilitação em longo prazo;

- função educativa ou docente que abrange as atividades educacionais, formais e informais, dirigidas ao paciente, família e comunidade; enfermeiros e equipe de enfermagem e interdisciplinar, além da elaboração de protocolos de seguimento e programas de educação permanente;

- função investigativa, na qual se inclui o desenvolvimento de pesquisas relacionadas à tecnologia do cuidar em estomaterapia e à avaliação de protocolos assistenciais e de equipamentos específicos;

- função administrativa dirigida ao controle e à avaliação em níveis assistencial e organizacional, incluindo o planejamento e organização de Programas e Serviços de Assistência Ambulatorial e Hospitalar; planejamento e distribuição de recursos humanos e materiais, além da consultoria e assessoria;

- desenvolvimento profissional que envolve a participação em atividades de educação permanente, além de com certificação periódica na especialização ${ }^{5}$; 
A amplitude de atuação do ET, no entanto, não lhe confere a prerrogativa do cuidar isolado, sendo indispensável à integração junto à equipe interdisciplinar e ao próprio estomizado e à família, todos devem participar como agentes ativos desse processo.

A construção de conhecimento científico que dê subsídios à prática clínica, por meio da pesquisa, constitui o grande desafio dessa especialidade.

\subsection{A Assistência de Enfermagem ao Estomizado Intestinal}

A assistência de enfermagem ao colostomizado deve possibilitar além da recuperação fisiológica, a retomada das atividades cotidianas com qualidade de vida, ou seja, o alcance da reabilitação.

As etapas do período perioperatório e as respectivas intervenções de enfermagem para as diferentes necessidades do futuro estomizado são descritas a seguir ${ }^{5}$.

O período pré-operatório inclui a abordagem sobre conhecimento do indivíduo acerca do diagnóstico e suas perspectivas; investigação dos antecedentes familiares e antecedentes alérgicos, hábitos e alterações de eliminação intestinal; utilização de medicamentos prévios; vida diária e possibilidade de atividades sociais e de trabalho. Além disso, outros aspectos do ensino pré-operatório, autocuidado, estado emocional, padrão sócio-cultural, estado nutricional, habilidades psicomotoras, topografia da parede abdominal, aspecto da região perineal e demarcação do estoma, também são importantes.

No trans-operatório o planejamento de enfermagem específico para este paciente envolve visita do enfermeiro do centro cirúrgico, padronização do equipamento a ser utilizado no pós-operatório imediato, que facilite a avaliação do estoma (bolsa coletora de peça única, transparente e drenável), verificação e avaliação do estoma confeccionado em 
relação à demarcação prévia e do estado geral do paciente antes do encaminhamento ao serviço de recuperação pós-anestésica, além dos cuidados básicos desenvolvidos no centro cirúrgico pela equipe de enfermagem ${ }^{5}$.

No período pós-operatório é necessário observar e avaliar condições do estoma (localização, coloração, protrusão e complicações); controlar qualitativamente e quantitativamente o efluente do estoma; avaliar adaptação do sistema coletor; realizar a primeira troca do sistema coletor (48 a 72 horas após a cirurgia); ensinar ações específicas do autocuidado (troca e esvaziamento do dispositivo); retomar o ensino pré-operatório e planejar a alta hospitalar; estimular o retorno gradual às atividades da vida diária; desenvolver trabalho multidisciplinar com nutricionista, psicólogo, equipe médica e fisioterapeuta; avaliar o aprendizado alcançado pelo paciente e familiar; fornecer equipamentos e encaminhar aos recursos da comunidade (Programa dos Ostomizados mantido pelo Sistema Único de Saúde) ${ }^{7}$.

Durante o período perioperatório o paciente apresenta ansiedade com relação ao procedimento cirúrgico, preocupações com sua família e trabalho, recuperação e condições físicas e psicológicas após a cirurgia. Especialmente, os pacientes candidatos a colostomia encontram-se preocupados com as mudanças no estilo de vida e alteração da imagem corporal, angustiam-se com a necessidade de autocuidado ("como cuidar da bolsa") e com aquisição de bolsas de colostomia ${ }^{8}$.

Após a alta hospitalar, os pacientes referem mudanças no estilo de vida, nas atividades de lazer, vida sexual, imagem corporal, vida social e alterações no corpo (aceitação do estoma, mudança do padrão de eliminação, complicações), além da adaptação necessária ao autocuidado ${ }^{9}$. 
Muitos estudos foram realizados desde o início da Estomaterapia no Brasil e existem estudos que afirmam a necessidade de sistematização da assistência ao estomizado intestinal, bem como, de sistemas gerenciais de avaliação que monitoram os processos e os resultados ${ }^{10}$

Com a sistematização da assistência há melhora na dinâmica do atendimento, padronização de registros, adequação de informação ao paciente e baixo índice de complicação de pele periestoma $(2,6 \%)$, proporcionando ao paciente e família maior segurança, aptidão ao autocuidado e promovendo assim uma reabilitação social precoce ${ }^{11}$.

Um dos aspectos mais importantes da assistência de enfermagem ao paciente é o seu acompanhamento após a alta hospitalar. Estudos apontam que a visita domiciliária constitui uma estratégia válida para o processo ensino-aprendizagem do paciente-família estomizado, tornando-se um instrumento indispensável na emancipação do paciente ${ }^{12}$.

O estomizado, durante o período perioperatório, enfrenta uma etapa difícil, que pode ser superada com a assistência multiprofissional que atenda as suas necessidades, com participação da família ${ }^{13}$.

O apoio familiar influencia diretamente no enfrentamento e na reabilitação do estomizado; portanto, é importante que o profissional conheça os fatores envolvidos na dinâmica familiar, para atuar integrado à família e ao paciente ${ }^{14}$.

As famílias de pacientes estomizados referem mudanças no estilo de vida e nas relações interpessoais após a confecção do estoma e reportam a necessidade de muitas informações sobre o tratamento, seus efeitos e demais cuidados ${ }^{15}$. 
O significado atribuído pelos clientes ao fato de ser portador de uma colostomia revela a possibilidade de um renascer para uma nova vida de saúde. Este significado não está associado à conotação de doença; mas associadas às estratégias utilizadas durante o processo de adaptação à nova condição de vida, que correspondem às soluções para os problemas. Trata-se de procedimentos práticos e simples, que advieram de um aprendizado resultante da convivência com a nova situação. Conclui-se ainda que a atividade educativa do enfermeiro junto aos clientes colostomizados deve favorecer a conscientização da situação que enfrentada e o reconhecimento da necessidade de desenvolver capacidades e habilidades para o autocuidado e possibilitar a sua independência e autonomia nessa nova forma de viver ${ }^{16}$.

Após o profundo impacto ocasionado pela doença e a estomia, as pessoas iniciam um processo de re-significação de suas identidades, que inclui um reposicionamento e um novo significado da cada uma delas perante a vida. As principais formas de ajustamento são: resignar-se positivamente com a situação, apegar-se a Deus e à religião, retomar as atividades anteriores, contar com o apoio da família e seus próximos, "administrar" a memória, entre outras. A manutenção da identidade restabelecida depende da habilidade que cada estomizado possui em responder aos eventos que vão surgindo, na trajetória de suas vidas ${ }^{17}$.

O enfermeiro deve planejar um cuidar holístico do ser humano portador de uma estomia, incorporando as dimensões afetivas, simbólicas e relacionais ${ }^{18}$.

Os enfermeiros caracterizam o estomizado como sendo um cliente que necessita de cuidados especiais, apontam as necessidades dos estomizados e apresentam seus 
conhecimentos para atender à clientela. Concluiu-se neste estudo que o cuidado com o os pacientes é inadequado, devido às várias limitações no conhecimento científico e ações dos enfermeiros ${ }^{19}$.

Um estudo etnográfico considera que o significado da experiência de ter uma colostomia é uma situação de ruptura biográfica. Há interrupção dos planos de vida, com necessidade de incorporação de práticas de cuidados específicos, como lidar com o estoma e até mesmo reformular suas expectativas de futuro. A participação de familiares e os profissionais que cuidam desses pacientes neste estudo dimensionou as dificuldades e o sofrimento dessas pessoas. A real finalidade do sistema de cuidado à saúde é integrar o portador de colostomia à sociedade como pessoa, incentivando-o a ter uma vida social $\operatorname{ativa}^{20}$.

Por outro lado, existem estudos que chamam a atenção dos enfermeiros sobre a importância da identificação de necessidades de aprendizagem dos estomizados e seus cuidadores e estas devem ser supridas por meio de uma abordagem pedagógica de conscientização, desenvolvida pelos enfermeiros ao longo da internação hospitalar ${ }^{21}$.

Frente a essas colocações, consideramos que os estudos realizados apresentam aspectos importantes sobre a assistência desse grupo de pacientes; porém, surgiu questionamento a respeito da aplicabilidade dos resultados e a fundamentação das ações em evidências científicas efetivas e eficazes. Justificamos a propriedade deste estudo diante das nossas reflexões. 


\section{2 . PROCEDIMENTOS METODOLÓGICOS}

\subsection{Referencial Teórico.}

$\mathrm{Na}$ era do conhecimento em que vivemos, a prática clínica e a educação profissional têm exigido evidências científicas para tomada de decisão e conduta pelo enfermeiro. Esse novo paradigma enfatiza a necessidade de incorporação de resultados de pesquisa ou outras evidências que dêem o embasamento ou justificativa para uma forma mais adequada para se realizar uma intervenção em saúde ${ }^{22}$.

A revisão sistemática e a revisão integrativa de literatura são recursos que possibilitam a incorporação das evidências científicas na prática.

A Prática Baseada em Evidências, movimento estruturado como facilitador da tomada de decisão, pode ser definido como um processo de busca, avaliação e aplicação de evidências científicas para tratamento e gerenciamento de saúde ${ }^{23}$.

A revisão sistemática preconizada na prática baseada em evidências, de acordo com a Colaboração Cochrane aponta que para a elaboração de uma revisão sistemática, o pesquisador deve buscar material publicado e não publicado visando à exaustão dos estudos na tentativa de diminuir possíveis vieses. Esta organização com centros em diferentes países, é responsável pelo desenvolvimento e disseminação de revisões sistemáticas que retratam a eficácia de intervenções na área da saúde e principalmente, os estudos incluídos nestas têm o delineamento de pesquisa experimental, ou seja, ensaios clínicos randomizados controlados ${ }^{24}$.

Na Medicina Baseada em Evidências, o estudo clínico controlado randomizado é considerado o delineamento de pesquisa mais adequado para avaliar a eficácia das 
intervenções em saúde, constituindo-se no "padrão ouro" deste movimento; entretanto na enfermagem este nível de evidência é restrito ${ }^{25}$.

A prática baseada em evidências em enfermagem pode trazer alterações no paradigma atual com valorização do pensamento crítico e dos conhecimentos dos profissionais da prática clínica ${ }^{26}$.

Atualmente os pesquisadores têm buscado as revisões sistemáticas de literatura para explicitar evidências científicas para determinada prática. A prática baseada em evidências têm sido aplicada na medicina e diversas outras áreas de saúde.

A medicina baseada em evidências é o processo sistemático de busca, avaliação e uso de resultados de pesquisas recentes como base para decisões clínicas; consiste na formulação de questionamento, descoberta e avaliação de dados relevantes e o aproveitamento dessas informações na prática clínica diária ${ }^{27}$.

A origem da Enfermagem Baseada em Evidências ocorreu juntamente com o movimento da Medicina Baseada em Evidências. A Enfermagem Baseada em Evidências não admite ações ritualísticas, experiência clínica isolada ou centrada em tarefas, opiniões infundadas ou tradição como a base para a prática de enfermagem, pois preconiza a utilização de resultados de pesquisa e dados oriundos de especialistas reconhecidos, com comprovação prática para a melhoria da qualidade do cuidado ${ }^{28}$.

Nas últimas décadas houve uma progressiva evolução na elaboração de revisões sistemáticas; entretanto, na enfermagem o desenvolvimento desta metodologia é limitado e os métodos empregados são derivados de outras disciplinas de saúde, principalmente da medicina $^{29}$. 
Ainda, os autores acima afirmam que as revisões sistemáticas enfocam primordialmente estudos experimentais, mais comumente estudos randomizados controlados. A finalidade destas revisões consiste na avaliação da eficácia de tratamento ou intervenção, assim esta metodologia responde prontamente as questões da medicina e falha em questões da enfermagem relacionadas ao cuidado ou ao impacto da doença ou $\operatorname{tratamento}^{29}$.

Desta forma para operacionalizar este estudo optamos pela revisão integrativa de literatura para melhor responder o questionamento sobre o conhecimento produzido sobre assistência de enfermagem hospitalar ao estomizado.

\subsection{Tipo de estudo}

A revisão integrativa de literatura propicia a síntese de conhecimento produzido sobre um determinado tema, permite a visualização de lacunas de evidências na prática profissional e viabiliza a contextualização do pesquisador em determinada temática. Acreditamos que este método contribuirá para o alcance dos objetivos propostos no trabalho.

A "literatura" consiste de todas as fontes escritas, relevantes para o tópico selecionado. A literatura publicada pode conter fontes primárias (escrita pela pessoa que o originou ou é responsável por gerar as idéias publicadas) ou secundárias (resume ou cita conteúdos de fontes primárias) ${ }^{30}$.

As revisões integrativas são conduzidas para identificar, analisar e sintetizar os resultados de estudos independentes, e determinar o conhecimento atual numa determinada área. 
A revisão integrativa é definida como uma revisão de pesquisas já realizadas e que são resumidas por meio de uma extração geral das conclusões de muitos estudos ${ }^{31}$.

O conceito subjacente à utilização da revisão integrativa, como método de pesquisa, é localizar e integrar as inferências de projetos de pesquisas primárias, tanto as premissas centrais na validação do conhecimento quanto às envolvidas na análise de dados originais. O objetivo maior é apresentar o estágio atual do conhecimento sobre aquele tópico específico ou lançar luzes sobre assuntos ainda não solucionados ${ }^{25}$.

A revisão integrativa possibilita um sumário das pesquisas já realizadas e permite obter conclusões sobre um tema de interesse. Uma revisão integrativa bem feita exige os mesmos padrões de rigor, de clareza e possibilidade de replicação de resultados utilizados nos estudos primários ${ }^{33}$.

Para condução de uma revisão integrativa devemos utilizar estratégias científicas que limitam o viés no levantamento das publicações, na análise crítica e na síntese dos resultados ${ }^{32}$.

A elaboração da revisão deve seguir padrões de rigor metodológico, os quais possibilitam ao leitor identificar as características reais dos estudos analisados ${ }^{34}$.

A revisão integrativa também permite ao pesquisador conhecer os profissionais que investigam o assunto de interesse, diferenciar evidência científica de opiniões de especialistas, estabelecer um panorama do conhecimento atual e as implicações do conhecimento científico na prática profissional ${ }^{35}$.

Este tipo de revisão é importante e sua realização consiste na possibilidade de oferecimento de subsídios para a implementação de modificações que promovam a qualidade das condutas assistenciais de enfermagem por meio de modelos de pesquisa ${ }^{36}$. 
Entendemos que este método insere-se na abordagem da Enfermagem Baseada em Evidências, visto que na nossa disciplina há poucos estudos experimentais, impossibilitando a realização de uma revisão com metanálise.

Para realização de nosso estudo seguiremos as fases propostas da revisão integrativa sugeridas por Ganong ${ }^{36}$, que são:

\section{Tarefa 1 - Selecionar as hipóteses ou questões para a revisão}

O tema de uma revisão integrativa deve ser claramente definido e especificado como uma questão ou hipótese de pesquisa primária. O tema deve ser relatado com teorias e conceitos já estabelecidos para fornecer base de conhecimento ao pesquisador e também deve ser amplo para propiciar uma revisão bibliográfica prévia.

\section{Tarefa 2 - Estabelecer critérios para seleção da amostra}

A seleção da amostra é importante, pois a sua representatividade é um indicador crítico de generalização das conclusões, confiabilidade e fidedignidade dos resultados.

A omissão dos procedimentos de amostragem pode colocar em risco a validade da pesquisa.

A conduta ideal é incluir todos os estudos encontrados, no entanto, se este procedimento for inviável pela quantidade de trabalhos, devem-se apresentar todos os critérios de inclusão e exclusão para seleção da amostra.

\section{Tarefa 3 - Apresentar as características da pesquisa primária}

Essa tarefa é a essência da revisão integrativa, pois é análoga à coleta de dados e ao relato dos dados da revisão.

Todas as características que podem influenciar os achados devem ser sistematicamente examinadas para que o objetivo da revisão seja completamente alcançado. 
Ganong enfatiza que o uso de tabelas torna a leitura mais simples, clara e objetiva, constituindo a forma mais indicada para expor a caracterização das pesquisas primárias analisadas $^{36}$.

\section{Tarefa 4 - Analisar os dados}

A análise dos dados deve ser feita de forma sistemática, expressando-se claramente as regras utilizadas. É importante a utilização de um protocolo para a leitura dos estudos e a coleta de dados.

O instrumento utilizado para a análise dos estudos deve ser explicado e disponibilizado aos leitores com o objetivo de não comprometer a validade dos resultados da revisão.

\section{Tarefa 5 - Interpretar os resultados}

A interpretação dos resultados é uma discussão sobre os trabalhos encontrados e direcionamento das pesquisas científicas na assistência de enfermagem hospitalar aos estomizados intestinais, identificação das necessidades de pesquisa para fundamentar cientificamente a prática atual e delimitação das prioridades de pesquisas futuras.

\section{Tarefa 6 - Apresentar a revisão}

A apresentação da revisão deve ser clara, completa e permitir que o leitor examine criticamente os resultados.

Acreditamos que estudos de revisão integrativa poderão trazer contribuições valiosas para a enfermagem, principalmente para indicar áreas de conhecimento que necessitam de estudos com delineamento de pesquisa "padrão-ouro", para fundamentar, cientificamente, as intervenções na prática clínica do enfermeiro. 


\subsection{Procedimentos para Seleção dos Artigos Científicos}

A questão formulada é: qual o conhecimento produzido e publicado na literatura nacional e internacional sobre assistência de enfermagem hospitalar ao estomizado intestinal?

A partir desta questão iniciamos a busca por literatura (livros, artigos, dissertações e teses) que pudessem contribuir para elucidar o questionamento.

Primeiramente realizamos a busca por artigos na base de dados da Bireme (www.bireme.br), utilizando como palavras-chave: estoma (descritor), "Estoma: construção de um orifício artificial para fistulização externa de um ducto ou vaso por inserção de um tubo com ou sem sonda hipotética" e enfermagem (aspecto).

Executamos a pesquisa em "Pesquisa Avançada", onde há possibilidade de limitar a pesquisa para "humanos" e "enfermagem". Deste modo otimizamos a pesquisa e automaticamente excluímos trabalhos de experimentação em animais e trabalhos que não são direcionados para assistência de enfermagem.

Pela Bireme é possível consultar simultaneamente as seguintes bases de dados: Lilacs (Literatura Latino-Americana e do Caribe em Ciências da Saúde), Medline 19661992 e 1993-2004 (Literatura Internacional em Saúde), Adolec (Saúde na Adolescência), Adsaúde (Administração de Serviços de Saúde), BBO (Bibliografia Brasileira de Odontologia), BDENF (Base de Dados de Enfermagem), HISA (História da Saúde Pública na América Latina e Caribe), Homeoindex (Homeopatia), LEYS (Legislação Básica de Saúde da América Latina e Caribe), MedCaribe (Literatura do Caribe em Ciências da Saúde), Repidisca (Literatura em Engenharia Sanitária e Ciências do Ambiente), OPAS (Acervo da Biblioteca da Organização Pan-Americana de Saúde), Wholis (Sistema de 
Informação da Biblioteca da OMS) e Desastres (Acervo do centro de Documentação de Desastres).

Além do site Bireme realizamos também a busca de teses no sistema Dedalus, que é a base de indexação da produção da Universidade de São Paulo (USP).

No Dedalus utilizamos como palavras-chave: colostomizado, ostomizado, colostomia, estoma e enfermagem, pois estes descritores ainda estão indexados nas bases de dados.

Estabelecemos como critérios de inclusão para seleção dos estudos: trabalhos que abordassem a assistência do estomizado intestinal hospitalizado, realizados com seres humanos e publicados em inglês, espanhol e português.

Os critérios de exclusão estabelecidos foram: trabalhos que abordassem outros tipos de estomas (não intestinais), trabalhos experimentais com animais, trabalhos direcionados à clientela infantil e trabalhos publicados em outros idiomas que não o inglês, o espanhol ou o português.

A amostra do estudo foi composta de trabalhos publicados nos últimos 05 anos (2002-2006) selecionados pelos critérios de inclusão e exclusão já citados, com um total de 22 trabalhos científicos.

O instrumento utilizado para coleta de dados foi o de Campos (Anexo A), adaptado para o objeto deste estudo. A adaptação do instrumento refere-se às categorias temáticas do estudo e delineamento utilizado ${ }^{37}$.

O instrumento contempla os seguintes dados:

- identificação (título do artigo, título do periódico, autores, país, idioma e ano de publicação); 
- instituição sede do estudo;

- periódico de publicação;

- características metodológicas do estudo (tipo de publicação, objetivo, população, amostra, tipo de desenho do estudo, aspectos abordados, categorização do tema e resultados e conclusões)

- base de dados;

- obtenção da pesquisa na íntegra.

Em 25/07/2006 realizamos uma busca bibliográfica e obtivemos uma amostra total de 256 referências na Base de Dados Medline, 15 no Lilacs e 18 no Dedalus.

Entretanto, por se tratar de um número inviável para leitura e análise, delimitamos a amostra de trabalhos científicos produzidos nos últimos 5 (cinco) anos, que abordassem a assistência de enfermagem hospitalar ao estomizado intestinal. Acreditamos que tal medida foi importante o alcance dos objetivos propostos neste trabalho.

Antes de aplicarmos o instrumento de pesquisa, foi realizada leitura criteriosa dos trabalhos para excluir os trabalhos não pertinentes ao tema e aqueles que não abordassem a assistência de enfermagem relacionada ao período hospitalar.

Após essa pré-análise aplicamos o instrumento de coleta de dados para análise e interpretação dos trabalhos.

Por meio deste referencial metodológico verificamos a produção científica existente sobre a assistência de enfermagem hospitalar ao estomizado intestinal, analisamos essa produção segundo área temática, origem dos autores e pertinência dos resultados e identificamos as prioridades de pesquisa. 


\section{ANÁLISE E DISCUSSÃO DOS RESULTADOS}

Da amostra inicial de 256 referências no Medline, 15 no Lilacs e 18 no Dedalus, excluímos $177(69,14 \%)$ dos $256(100 \%)$ trabalhos encontrados no Medline no período de 1996 a 2001, $09(60 \%)$ dos $15(100 \%)$ do Lilacs e $6(33,3 \%)$ dos 18 (100\%) do Dedalus. Com a exclusão de 192 trabalhos, houve diminuição de 66,5\% da amostra inicial deste estudo, que era constituída de 289 trabalhos científicos.

Da amostra do Medline, com a exclusão dos 177 trabalhos do período de 1996 a 2001, resultou uma amostra de 79 trabalhos científicos. Deste total, excluímos 5 por não focalizarem o tema de nosso estudo (estomia intestinal), após leitura do resumo e do artigo na íntegra. Ainda excluímos 10 trabalhos por não estarem relacionados ao tema, 29 que não configuram trabalho científico (editoriais, opinião de especialista, etc.), 5 redigidos em outros idiomas (4 em francês e 1 em alemão). Além destes, outros 16 trabalhos foram excluídos por não estarem disponibilizados na íntegra (escrito ou on-line) ou por não terem sido obtidos até a data limite, estabelecida para a inclusão no estudo, pelo sistema de comutação de textos, via biblioteca da Universidade de São Paulo. Portanto, totalizaram 242 trabalhos científicos excluídos e a amostra final da Base Medline foi constituída de 14 trabalhos conforme fluxograma a seguir. 
FLUXOGRAMA BASE DE DADOS - MEDLINE

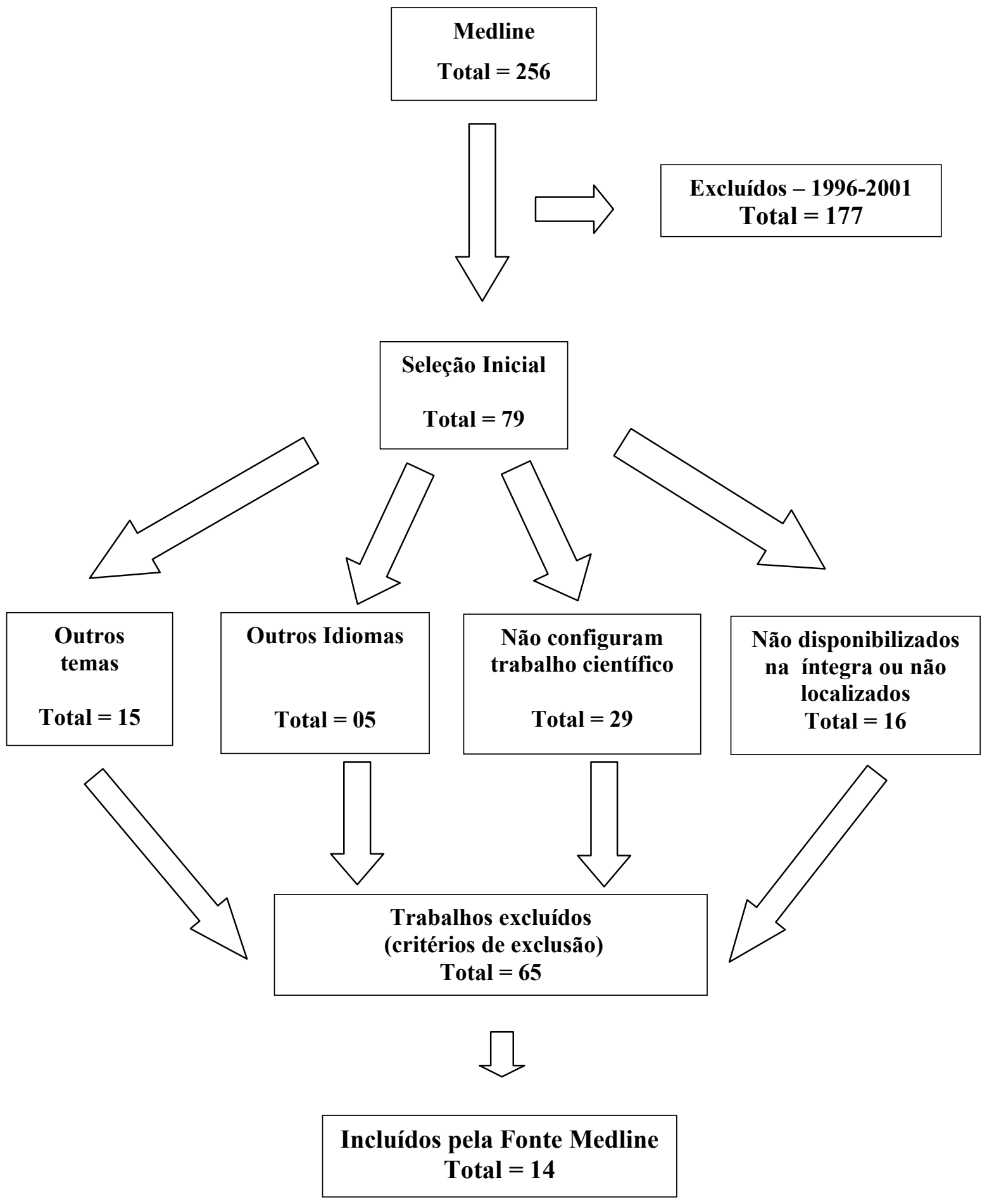


Na Base de Dados Lilacs, a amostra inicial foi constituída de 15 trabalhos científicos, dos quais 09 foram excluídos por serem produção do período de 1996-2001, 02 por abordarem outros temas e 03 por já estarem incluídos na amostra da Base Medline. Desta forma selecionamos apenas 01 trabalho científico conforme ilustra fluxograma abaixo.

FLUXOGRAMA BASE DE DADOS - LILACS

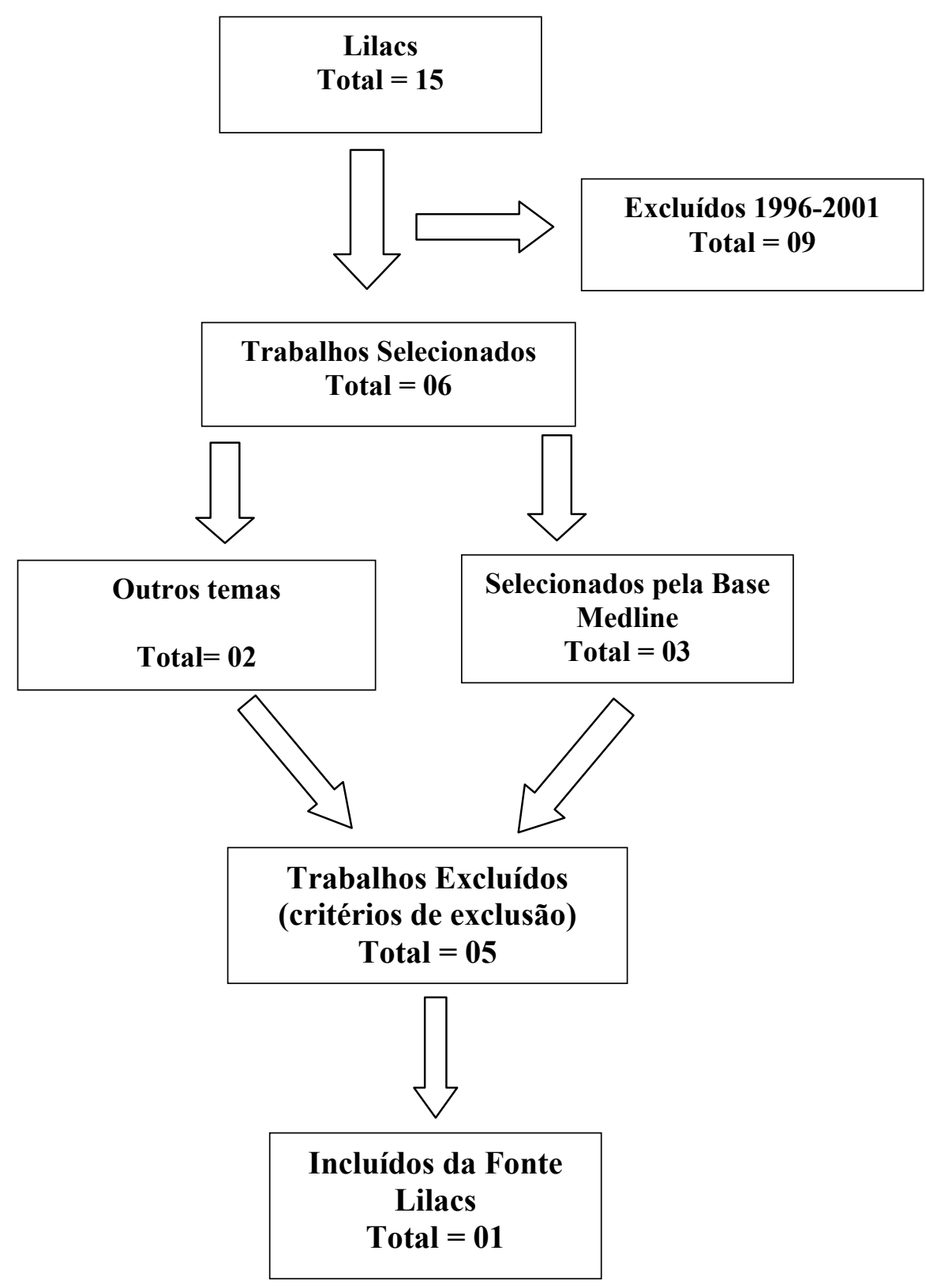


Na Base de Dados Dedalus, da seleção inicial foi de 18 trabalhos científicos, destes excluímos 06 por serem publicações do período anterior a 2001 e 05 por já estarem selecionados pelas fontes Medline e/ou Lilacs. Portanto, selecionamos para análise 07 trabalhos científicos nesta fonte. O fluxograma abaixo ilustra essa seleção.

\section{FLUXOGRAMA DEDALUS}
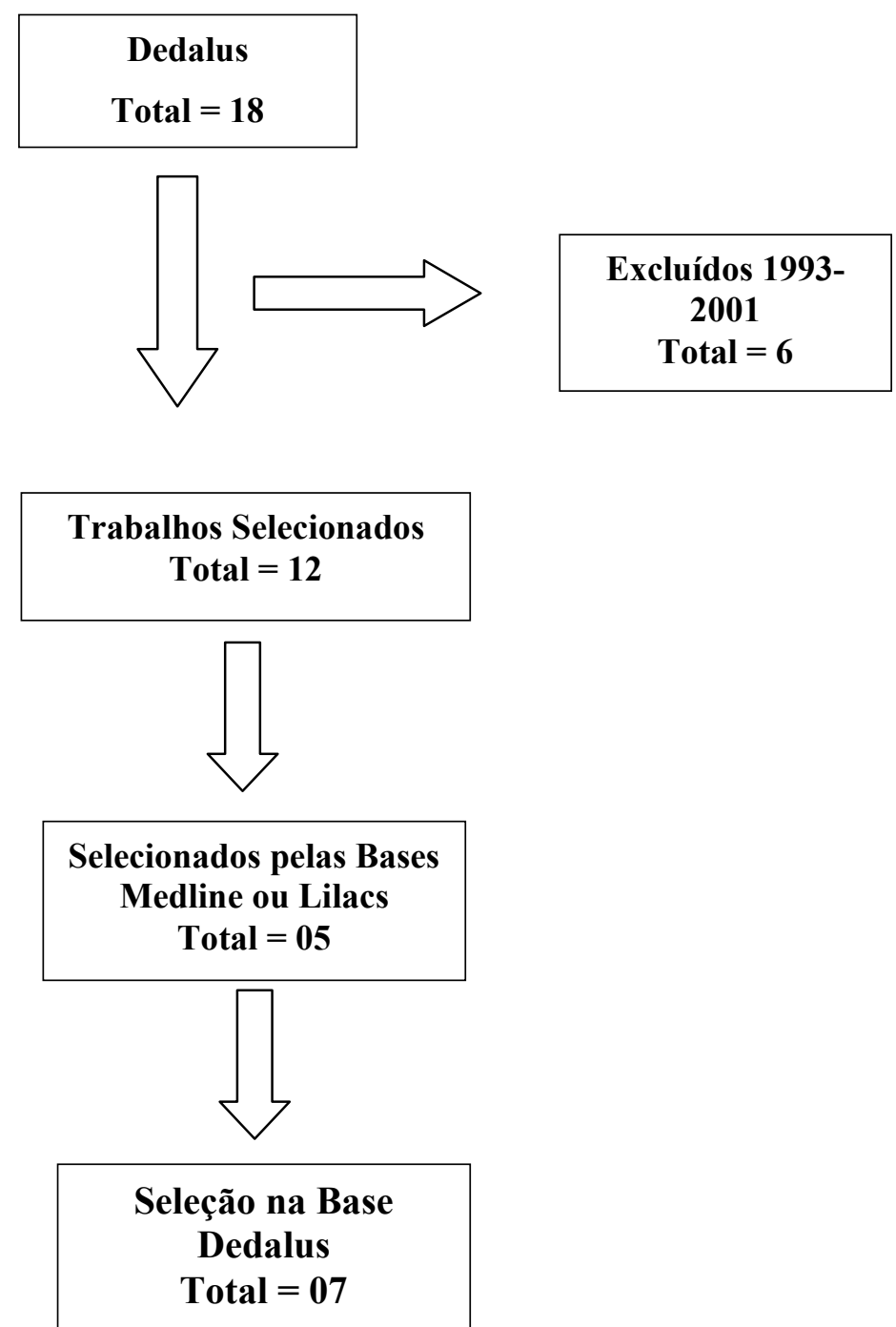
Portanto, o resultado das buscas realizadas nas três Bases de Dados foi de 289 trabalhos científicos. Ao excluirmos os trabalhos publicados no período entre 1993 e 2001 , totalizamos 192 trabalhos. Destes, 75 foram excluídos mediante os critérios de exclusão e a nossa amostra para a realização deste estudo foi constituída por 22 trabalhos científicos.

\section{FLUXOGRAMA GERAL DA BUSCA}

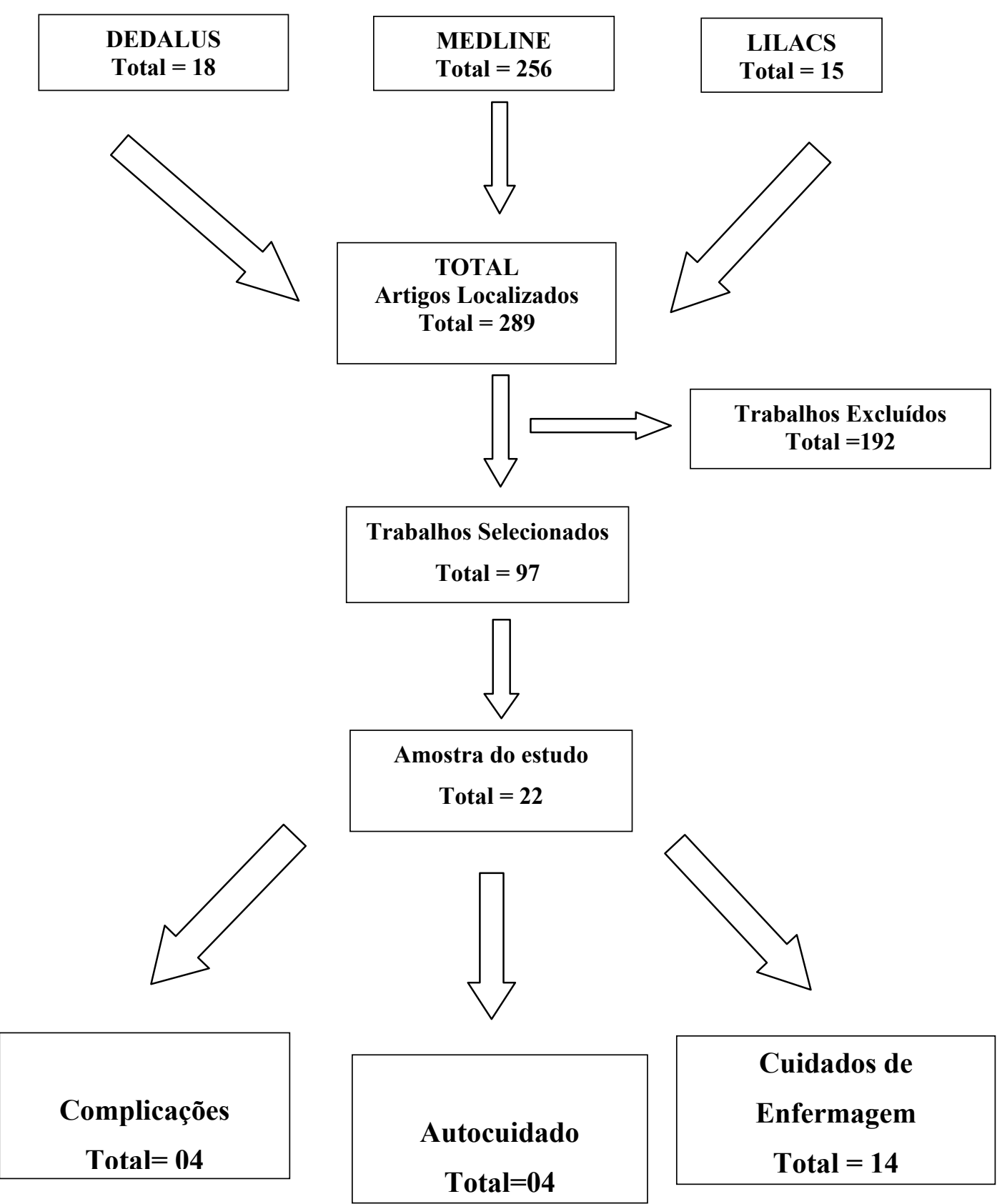


Após a seleção dos trabalhos científicos, foi realizada leitura criteriosa de todos os trabalhos científicos na íntegra, com aplicação do instrumento de coleta de dados para categorização dos temas.

\subsection{Caracterização dos estudos selecionados}

Apresentaremos a caracterização dos vinte e dois trabalhos científicos, que constituíram a amostra do nosso estudo.

Do total de vinte e dois $(100 \%)$ trabalhos, tivemos dezoito $(81,8 \%)$ produzidos por dois ou mais autores. Ao considerar a primeira autoria tivemos vinte $(90,4 \%)$ enfermeiros, um (4,5\%) supervisor de ensino e um (4,5\%) aluno de graduação; oito $(36,3 \%)$ atuavam em universidades, sete $(31,8 \%)$ em instituições hospitalares e sete $(31,8 \%)$ não citavam o local de atuação profissional.

Ao analisar os dezoito (100\%) trabalhos publicados por dois ou mais autores, verificamos a profissão e local de atuação da segunda autoria e obtivemos dezesseis $(88,8 \%)$ enfermeiros, um (5,5\%) pedagoga e um (5,5\%) não constava a profissão; cinco $(27,7 \%)$ trabalhavam em instituições hospitalares, oito $(36,3 \%)$ em universidades e cinco $(27,7 \%)$ não citavam o local de trabalho.

Houve um número maior da produção brasileira com nove $(40,9 \%)$ trabalhos científicos.

Os critérios estabelecidos em relação ao idioma, a dificuldade de acesso aos periódicos não disponíveis eletronicamente e a possibilidade de livre acesso à produção da Universidade de São Paulo foram fatores determinantes para predominância de trabalhos de autores brasileiros em nossa amostra. 
O tipo de publicação predominante foi em forma de artigo científico com dezoito $(81,8 \%)$ trabalhos, três $(13,6 \%)$ na forma de dissertação de mestrado e um $(4,5 \%)$ tese de doutorado.

Observamos com este resultado que a investigação sobre a assistência de enfermagem aos estomizados nos cursos de pós-graduações stricto sensu ainda é pouco explorada.

Os periódicos de publicação destes trabalhos foram diversos. Identificamos quatro $(18,2 \%)$ publicações no periódico Nursing Standard, três $(13,6 \%)$ no British Journal Nursing, três $(13,6 \%)$ no Ostomy Manage Nursing, dois $(9,1 \%)$ na Revista Latino Americana de Enfermagem (Ribeirão Preto), um (4,5\%) no Complement Ther Nurs Midwifery, um (4,5\%) no Gastroenterology Nursing, um (4,5\%) na revista Nursing (São Paulo), um (4,5\%) na Revista Brasileira de Cancerologia (Rio de Janeiro), um (4,5\%) na $\mathrm{RN}$, quatro $(18,2 \%)$ teses e dissertações oriundos dos cursos de pós-graduação da Universidade de São Paulo (USP) e um (4,5\%) no Simpósio Internacional de Iniciação Científica da Universidade de São Paulo (SIICUSP).

Obtivemos oito (36,3\%) trabalhos na íntegra no Núcleo de Apoio Bibliográfico Glete de Alcântara da Escola de Enfermagem de Ribeirão Preto.

A busca por meio digital pode ser realizada pelo site Bireme (www.bireme.br), no qual obtivemos dez $(45,5 \%)$ trabalhos e com o sistema COMUT (comutação bibliográfica a nível nacional e internacional, com solicitação on-line) obtivemos quatro $(18,2 \%)$ trabalhos na íntegra. 
Dos vinte e dois (100\%) estudos incluídos na revisão integrativa, catorze $(63,6 \%)$ trabalhos científicos foram categorizados em Cuidados de Enfermagem, quatro (18,2\%), em Autocuidado e quatro (18,2\%) em Complicações.

Na categoria de temas Cuidados de Enfermagem foram incluídos os trabalhos que abordavam a assistência de enfermagem no período perioperatório, que exploravam o planejamento de cuidados ao estomizado intestinal, além de aspectos conceituais técnicos, sob a perspectiva do paciente e/ou do familiar e do profissional.

Os estudos categorizados como Autocuidado aprofundavam as situações clínicas e estratégias propícias para que os profissionais realizem a atividade de ensino do autocuidado, assim como outros aspectos importantes, a sexualidade e a imagem corporal do estomizado intestinal.

Na categoria de temas Complicações, os estudos abordavam aspectos de prevenção e tratamento das complicações dos estomas intestinais.

A caracterização dos textos com respectivos autores e delineamentos está ilustrada nos quadros seguintes. 


\begin{tabular}{|c|c|c|c|c|c|}
\hline $\begin{array}{c}\mathrm{N} \\
\mathrm{o}\end{array}$ & AUTOR & $\overline{\mathrm{ANO}}$ & PAÍS & TIPO DE PESQUISA & CATEGORIA \\
\hline 1 & $\begin{array}{l}\text { Fleischer, I; } \\
\text { Bryant, D }\end{array}$ & 2005 & $\begin{array}{l}\text { Estados } \\
\text { Unidos }\end{array}$ & Relato de Caso & $\begin{array}{l}\text { Cuidados de } \\
\text { Enfermagem }\end{array}$ \\
\hline 2 & $\begin{array}{l}\text { Persson, E; } \\
\text { Wilde } \\
\text { Larsson,B }\end{array}$ & 2005 & $\begin{array}{l}\text { Estados } \\
\text { Unidos }\end{array}$ & $\begin{array}{c}\text { Quantitativo } \\
\text { Descritivo Exploratório }\end{array}$ & $\begin{array}{l}\text { Cuidados de } \\
\text { Enfermagem }\end{array}$ \\
\hline 3 & Ringhofer, $\mathrm{J}$ & 2005 & $\begin{array}{l}\text { Estados } \\
\text { Unidos }\end{array}$ & Estudo Teórico & $\begin{array}{l}\text { Cuidados de } \\
\text { Enfermagem }\end{array}$ \\
\hline $\begin{array}{l}4 \\
5\end{array}$ & $\begin{array}{l}\mathrm{O}^{\prime} \text { Connor G } \\
\text { Hollinworth H; } \\
\text { et. al. }\end{array}$ & $\begin{array}{l}2005 \\
2004\end{array}$ & Inglaterra & Estudo Teórico & $\begin{array}{l}\text { Autocuidado } \\
\text { Autocuidado }\end{array}$ \\
\hline 6 & $\begin{array}{l}\text { Gallagher S; } \\
\text { Gates J }\end{array}$ & 2004 & $\begin{array}{l}\text { Estados } \\
\text { Unidos }\end{array}$ & Estudo Teórico & $\begin{array}{l}\text { Cuidados de } \\
\text { Enfermagem }\end{array}$ \\
\hline $\begin{array}{l}7 \\
8\end{array}$ & $\begin{array}{l}\quad \text { Black PK } \\
\text { Boyd K; } \\
\text { Thompson MJ; } \\
\text { Boyd-Carson W; } \\
\text { Trainor B }\end{array}$ & 2004 & Inglaterra & $\begin{array}{l}\text { Estudo Teórico } \\
\text { Estudo Teórico }\end{array}$ & $\begin{array}{l}\text { Autocuidado } \\
\text { Complicações }\end{array}$ \\
\hline 9 & $\begin{array}{l}\text { Aukamp V; } \\
\text { Sredl D }\end{array}$ & 2004 & Escócia & Revisão Bibliográfica & $\begin{array}{l}\text { Cuidados de } \\
\text { Enfermagem }\end{array}$ \\
\hline 10 & $\begin{array}{c}\text { Boyd-Carsson } \\
\text { W; Thompson } \\
\text { MJ; Trainor B; } \\
\text { Boyd K }\end{array}$ & 2004 & Inglaterra & Estudo Teórico & Complicações \\
\hline 11 & $\begin{array}{c}\text { Rutledge M; } \\
\text { Thompson MJ; } \\
\text { Boyd-Carson } \\
\text { W }\end{array}$ & 2003 & Inglaterra & Estudo Teórico & Complicações \\
\hline 12 & $\begin{array}{c}\text { Trainor B; } \\
\text { Thompson MJ; } \\
\text { Boyd-Carson } \\
\text { W; Boyd K }\end{array}$ & 2003 & Inglaterra & Estudo Teórico & Complicações \\
\hline 13 & Hyland J & 2003 & $\begin{array}{l}\text { Estados } \\
\text { Unidos }\end{array}$ & Estudo Teórico & $\begin{array}{l}\text { Cuidado de } \\
\text { Enfermagem }\end{array}$ \\
\hline 14 & $\begin{array}{l}\text { Gemelli LM; } \\
\text { Zago MM }\end{array}$ & 2002 & Brasil & $\begin{array}{c}\text { Qualitativo } \\
\text { Estudo de Caso }\end{array}$ & $\begin{array}{l}\text { Cuidados de } \\
\text { Enfermagem }\end{array}$ \\
\hline
\end{tabular}

QUADRO 4: Estudos incluídos na revisão integrativa sobre assistência de enfermagem hospitalar aos estomizados intestinais. Ribeirão Preto - São Paulo, 2007. Fonte Medline. 


\begin{tabular}{llcccc}
\hline $\begin{array}{c}\mathrm{N} \\
\mathrm{o}\end{array}$ & AUTOR & AN & PAÍ́S & TIPO DE PESQUISA & CATEGORIA \\
\hline 15 & $\begin{array}{l}\text { Borges, Eline Lima; } \\
\text { Carvalho, Daclé Vilma }\end{array}$ & 2002 & Brasil & $\begin{array}{c}\text { Quantitativo } \\
\text { Retrospectivo Descritivo }\end{array}$ & $\begin{array}{c}\text { Cuidados de } \\
\text { Enfermagem }\end{array}$ \\
\hline
\end{tabular}

QUADRO 5: Estudo incluído na revisão integrativa sobre assistência de enfermagem hospitalar aos estomizados intestinais. Ribeirão Preto - São Paulo, 2007. Fonte Lilacs

\begin{tabular}{llcccc}
\hline $\mathrm{N}^{\mathrm{o}}$ & AUTOR & ANO & PAÍS & TIPO DE PESQUISA & CATEGORIA \\
\hline 16 & Sonobe & 2002 & Brasil & Qualitativo Etnográfico & $\begin{array}{c}\text { Cuidados de } \\
\text { Enfermagem }\end{array}$ \\
17 & Poggetto & 2002 & Brasil & Qualitativa Pesquisa Participante & $\begin{array}{c}\text { Cuidados de } \\
\text { Enfermagem }\end{array}$ \\
18 & Bezerra & 2002 & Brasil & Revisão Bibliográfica & $\begin{array}{c}\text { Cuidados de } \\
\text { Enfermagem }\end{array}$ \\
19 & Maruyama & 2004 & Brasil & Qualitativo Etnográfico & $\begin{array}{c}\text { Cuidados de } \\
\text { Enfermagem }\end{array}$ \\
20 & Maruyama & 2005 & Brasil & $\begin{array}{c}\text { Qualitativo Etnográfico } \\
\text { Cuidados de } \\
\text { Enfermagem }\end{array}$ \\
& Kameo & 2006 & Brasil & $\begin{array}{c}\text { Quantitativo Descritivo } \\
\text { Exploratório }\end{array}$ & $\begin{array}{c}\text { Cuidados de } \\
\text { Enfermagem }\end{array}$ \\
& & & Brasil & Quantitativo Descritivo & Autocuidado \\
\hline
\end{tabular}

QUADRO 6: Estudos incluídos na revisão integrativa sobre assistência de enfermagem hospitalar aos estomizados intestinais. Ribeirão Preto - São Paulo, 2007. Fonte Dedalus

Constatamos que nove (41\%) trabalhos da nossa amostra eram estudos teóricos.

Os trabalhos identificados como estudos teóricos referem-se àqueles que emitiam uma opinião de um profissional ou mapeamento acerca da assistência de enfermagem, com citações de vários autores e estudos científicos sobre o tema. Entretanto, tais estudos não constituem revisões de literatura por não ter sido realizado uma busca ampla, com inclusão de todos os estudos do tema explorado e também não foi possível identificar todas as 
características de um método de pesquisa como a Teoria Fundamentada de Dados, apesar de alguns nuances presentes nestes trabalhados analisados nesta categoria.

A Teoria Fundamentada de Dados é uma abordagem qualitativa que utiliza o método da comparação constante de análise de dados ${ }^{38}$. É uma linha de raciocínio indutiva que programa um conjunto sistemático de procedimentos para chegar à teoria sobre os processos sociais básicos ${ }^{39}$.

Os estudos categorizados como teóricos trazem contribuição para os enfermeiros generalistas porque fornecem informações importantes para a prática clínica profissional, mas não atendem todos os critérios de rigor científico no que se refere ao delineamento da pesquisa, que á condição que assegura a confiabilidade e evidência científica sobre um determinado tema e contribui no desenvolvimento da enfermagem enquanto ciência.

Para maior compreensão da revisão de literatura, apresentamos os aspectos importantes que devem ser utilizados na elaboração de estudo que adotam este procedimento metodológico.

A revisão narrativa tradicional de literatura é uma revisão que sintetiza e resume, em termos narrativos, um corpo de literatura de pesquisa. Estas revisões podem ter diferentes finalidades como fornecer informação de vanguarda, baseada em pesquisa científica, aos profissionais que exercem enfermagem; fornecer fundamentos para o desenvolvimento de inovações para a prática clínica, bem como identificar necessidades de futuras pesquisas ${ }^{38}$.

Obtivemos duas $(9,1 \%)$ revisões narrativas de literatura. A revisão de literatura é, tradicionalmente, considerada uma revisão sistemática e crítica das literaturas especializadas mais importantes publicadas a respeito de um tópico específico. O termo literatura especializada pode referir-se a literatura de banco de dados (de pesquisa) 
publicada ou não, bem como materiais de literatura conceitual, encontrados sob forma impressa ou não. Literatura de banco de dados são relatórios de pesquisas concluídas. Literatura conceitual abarca relatórios de teoria, alguns dos quais são subjacentes ao relatório de pesquisa, bem como outro material de pesquisa a ser consumido ${ }^{39}$.

A meta-análise é outra forma de revisão de literatura quando o método é de integração estatística dos resultados da pesquisa quantitativa. Os resultados de múltiplos estudos sobre o mesmo tópico são combinados para criar um conjunto de dados. Tipicamente, a meta-análise busca as informações sobre a força da relação entre as variáveis independentes e dependentes de cada estudo, quantifica essa informação e posteriormente faz uma média dos resultados ${ }^{38}$. É considerado o tipo de estudo de maior força de evidência científica.

Temos ainda as revisões sistemáticas, que do ponto de vista conceitual, são intrinsecamente investigações científicas, com métodos pré-planejados e que reúnem estudos originais como amostra. Elas sintetizam os resultados de múltiplas investigações primárias, usando estratégias que limitam os vieses e os erros aleatórios (randômicos). Em geral, o autor destas revisões segue uma seqüência metodológica que visa garantir a (força) consistência das conclusões oriundas desta sistematização ${ }^{40}$. As revisões sistemáticas buscam exaustivamente localizar toda a literatura impressa ou não, publicada ou não sobre o tema escolhido, além de considerar preferencialmente, os estudos que possuem evidência forte (randomizados controlados).

Tanto as revisões sistemáticas quanto narrativas, embora sejam diferentes na abrangência da busca e compilação dos resultados, requerem rigor metodológico no que se refere à especificação do tema (problema), definição da abrangência da busca, definição 
dos critérios de exclusão e inclusão, análise e interpretação dos artigos e apresentação dos resultados.

Devem, portanto, seguir um planejamento apropriado mínimo que apresente determinação clara do tema a ser revisado; identificação, seleção e avaliação crítica da qualidade dos estudos a serem incluídos na revisão; coleta e síntese das informações relevantes e elaboração das conclusões ${ }^{40}$.

As revisões de literatura devem seguir as etapas preconizadas de um tipo de revisão (sistemática, meta-análise, integrativa ou narrativa) para que possam constituir um trabalho científico.

Analisamos três $(13,7 \%)$ trabalhos científicos na abordagem qualitativa que foram produzidos com o método etnográfico, um $(4,5 \%)$ estudo de caso e um $(4,5 \%)$ pesquisa participante.

O método etnográfico concentra-se nas descrições científicas de grupos culturais. Os enfermeiros têm adotado este método para estudar variações culturais na saúde e de grupos de pacientes como subculturas dentro de contextos sociais mais amplos. O etnógrafo escolhe um grupo que vive o fenômeno de investigação de seu interesse. A organização dos dados envolve observação participante ou imersão no cenário, entrevistas de informantes e interpretação de padrões culturais pelo pesquisador ${ }^{39}$.

Três tipos de informação são geralmente buscados pelos etnógrafos: o comportamento cultural (o que fazem os membros da cultura); os artefatos da cultura (o que os membros da cultura fazem e usam) e a fala cultural (o que as pessoas dizem). Os produtos da pesquisa etnográfica são descrições ricas e holísticas da cultura sob estudo. Os etnógrafos também fazem interpretações da cultura, descrevendo seus padrões normativos, 
comportamentais e sociais. A investigação etnográfica facilita a compreensão dos comportamentos que afetam a saúde e a doença ${ }^{38}$.

O método do estudo de caso, utilizado na elaboração de trabalhos científicos, concentra-se num fenômeno contemporâneo selecionado para proporcionar uma descrição aprofundada de suas dimensões e processos essenciais ${ }^{39}$.

Um dos trabalhos analisados utilizou o referencial metodológico da pesquisa participante em seu estudo e refere que este auxilia a população na identificação de seus problemas, levando-a a análise crítica dos mesmos e a buscar soluções apropriada.A obtenção de dados descritivos tem o ambiente como fonte das informações ${ }^{40}$.

No tipo de pesquisa classificada como "relato de caso", verificamos que os trabalhos trazem descrição detalhada e análise crítica de um caso típico ou atípico. Neste tipo de artigo o autor apresenta um problema em seus múltiplos aspectos e sua relevância, com revisão bibliográfica sobre o tema.

$\mathrm{Na}$ abordagem quantitativa localizamos três $(13,7 \%)$ trabalhos com método descritivo exploratório e um (4,5\%) retrospectivo descritivo.

A pesquisa descritiva é uma classe da pesquisa não-experimental cuja finalidade é observar, descrever e documentar os aspectos de uma situação ${ }^{38}$.Estudos descritivoexploratórios, também chamados de levantamentos (surveys), coletam descrições detalhadas de variáveis existentes e usam dados para justificar e avaliar condições práticas correntes. Os investigadores usam esse desenho para buscar informações sobre as características dos sujeitos de pesquisa, grupos, instituições ou situações, ou sobre a freqüência de ocorrência de um fenômeno, particularmente quando se sabe pouco sobre o 
fenômeno. Os tipos de variáveis de interesse podem ser classificadas como opiniões, atitudes ou fatos ${ }^{39}$.

Já nos estudos descritivos retrospectivos a variável dependente já foi afetada pela variável independente, e o investigador busca relacionar acontecimentos presentes com os que ocorreram no passado ${ }^{39}$.

Com estes resultados sobre a análise dos métodos utilizados nos trabalhos sobre a assistência de enfermagem hospitalar ao estomizado intestinal podemos concluir que ainda não identificamos trabalhos com nível forte de evidência para realizarmos revisões sistemáticas sobre determinada intervenção ou procedimento clínico.

A busca de evidências é orientada por sua relevância e qualidade. Com base na hierarquia da evidência, procura-se detectar artigos, cuja metodologia empregada seja consistente e comprometida com o controle de vieses ${ }^{41}$.

Os tipos e níveis de evidência, em ordem decrescente de evidência são:

I - Evidência forte de, pelo menos, uma revisão sistemática (meta-análise) de múltiplos estudos randomizados controlados bem delineados.

II - Evidência forte de, pelo menos, um estudo randomizado controlado bem delineado, de tamanho adequado e com contexto clínico apropriado.

III - Evidência de estudo, sem randomização, com grupo único, com análise pré e póscoorte, séries temporais ou caso-controle pareados.

VI - Evidência de estudos bem delineados não-experimentais, realizados em mais de um centro de pesquisa.

V - Opiniões de autoridades respeitadas, baseadas em evidência clínica, estudos descritivos e relatórios de comitês de expertos ou consensos. 
Especificamente para a área da enfermagem existe a necessidade de maior investimento em estudos com alto nível de evidência com o desenvolvimento de revisões sistemáticas que assegurem a prática clínica, bem como de estudos com estrutura metodológica melhor delineada.

Contudo, as revisões sistemáticas ainda não possuem uma definição ou formatação que alcance os estudos de abordagem qualitativa que buscam a compreensão holística dos significados do processo saúde e doença. A enfermagem está diretamente envolvida, não somente, com o processo fisiológico do adoecer e dos processos de cura, mas com a inserção biopsicossocial do ser humano nas diferentes situações, que envolvem o cuidar humano.

Para evoluir como ciência, a enfermagem necessita de desenvolvimento de estudos, tanto quantitativos, de evidência forte para prática clínica como de estudos qualitativos que auxiliem na compreensão dos significados psico-sócio-culturais dos processos de saúde e doença.

\subsection{Assistência de enfermagem hospitalar aos estomizados intestinais}

A análise dos vinte e dois estudos da amostra deste estudo possibilitou sintetizar o conhecimento da literatura nacional e internacional sobre a assistência de enfermagem hospitalar ao estomizado intestinal e culminou em três categorias temáticas: Cuidados de Enfermagem, Autocuidado e Complicações.

Passaremos a descrever cada um dos estudos, que compuseram a categoria Cuidados de Enfermagem.

O planejamento da assistência em estomaterapia requer o conhecimento do perfil da clientela atendida para definição e organização do atendimento. Neste estudo retrospectivo 
descritivo os objetivos foram caracterizar o grupo de portadores de estoma atendidos no setor de estomaterapia, identificar as orientações fornecidas no pré-operatório e o grau de percepção dos clientes sobre as orientações recebidas. O estudo engloba a identificação dos pacientes, dados clínicos e exame físico; avaliação da pele periestoma; aspecto do efluente; autocuidado; complicações e adaptação aos equipamentos utilizados ${ }^{42}$.

O conhecimento do perfil da clientela direciona a assistência no planejamento de recursos humanos e materiais, necessidades educativas, dinâmica familiar e inserção social do paciente. Como existe uma grande diversidade de equipamentos para estomizados disponíveis no mercado, é essencial o conhecimento das necessidades dos pacientes para efetividade e resolução do atendimento prestado.

Identificamos também estudos qualitativos que investigaram o significado do adoecer e do uso da bolsa para os pacientes. Um estudo exploratório com abordagem qualitativa sobre a visão do colostomizado sobre o uso da bolsa de colostomia analisou os dados duas categorias: o reconhecimento das limitações e mudanças ocorridas e as possibilidades após o uso da bolsa de colostomia. As autoras consideram que o paciente necessita viver seu momento de luto, de perdas, para encontrar forças para aceitar e trabalhar suas perspectivas. A resolução das dificuldades depende dos recursos internos e do suporte social fornecido pela família, pelos profissionais e estrutura de atendimento oferecida ${ }^{8}$.

Estudos desta natureza contribuem para compreensão da experiência vivida pelo paciente, e pontuam aspectos psicológicos do paciente que devem ser considerados durante a assistência hospitalar. 
O ensino do paciente também foi tema do estudo de um que discute as estratégias norteadoras da assistência de enfermagem. A autora desenvolveu um estudo qualitativo abordando as mudanças físicas e psicossociais e as conquistas alcançadas pelos pacientes neste percurso. O significado de ser portador de uma colostomia, na perspectiva dos pacientes, revela a possibilidade de uma nova vida, isenta de conotação de doença e as estratégias utilizadas para adaptação à nova condição correspondem às possibilidades de cada indivíduo ${ }^{40}$.

A análise da literatura sobre o registro de enfermagem com colostomizados mostra o interesse crescente em revisões bibliográficas e de literatura na estomaterapia. Foi realizada uma análise de literatura sobre o registro de enfermagem com colostomizados, entretanto não foram encontrados trabalhos específicos sobre o registro de enfermagem. A revisão de literatura possibilitou atualização no contexto em que se insere a estomaterapia e definição de problemas a serem estudados em pesquisas futuras ${ }^{43}$.

O investimento na realização de trabalhos que buscam evidências científicas por meio de revisão integrativa em temas específicos da estomaterapia ainda é incipiente. À medida que forem realizadas investigações sobre os diversos aspectos envolvidos no cuidado do estomizado as intervenções e estratégias serão cientificamente mais efetivas na prática clínica e assistencial do enfermeiro.

Muitos pesquisadores têm buscado investigar a qualidade de vida dos pacientes estomizados e a compreensão do fenômeno vivido por eles.

Um estudo qualitativo etnográfico sobre a experiência da colostomia por câncer considerou o significado como ruptura biográfica na visão dos portadores, familiares e 
profissionais de saúde. O estudo possibilitou compreender que o destino, o sofrimento e a individualidade se integram de forma lógica no fenômeno como uma ruptura biográfica, na visão dos sujeitos, que deve ser considerada pelos profissionais ${ }^{44}$. O processo de adoecer entre portadores de colostomia por câncer e seus familiares foi pesquisado em um estudo etnográfico e as autoras identificaram como categoria principal - "a vida antes da colostomia por câncer e o processo do adoecer"- da qual foram extraídas seis subcategorias: aspectos marcantes da vida antes da colostomia, a entrada da pessoa no reino da doença, a busca por ajuda para sua doença, o corpo como locus do câncer, as explicações para o câncer e os estigmas do câncer. A análise das categorias permitiu concluir que as narrativas da vida, antes do adoecimento, demonstram que as experiências do processo de adoecer dão origem a novos significados em virtude das diversas experiências individuais e relacionam com o contexto de vida, a família e as atividades. Portanto a experiência de ter uma colostomia por câncer é uma construção cultural ${ }^{45}$.

Um dos trabalhos analisados avaliou a correlação entre a qualidade de vida e as características sócio-demográficas, localização do tumor e tipo de estoma, entre colostomizados. Foram utilizados os instrumentos de Escala de Qualidade de Vida de Flanagan (EQVF) e o EORTC-QLQ-C-30. Na análise comparativa verificou-se que pacientes portadores de estoma com menos de um ano apresentam maior atividade social do que aqueles com mais de um ano de estoma; a função física teve maior média em pessoas casadas; a presença de dor foi maior entre o grupo de pessoas viúvas e separadas; a dispnéia teve maior média entre aqueles com metástase; na escala de saúde mental foram estatisticamente significativos o sexo e as complicações, com médias superiores entre aqueles do sexo masculino e com presença de complicações; as escalas de função 
emocional, dispnéia, dificuldade financeira, e estado geral de saúde tiveram influência das variáveis como sexo, estado civil, estado de procedência, metástase, tempo de estoma e complicações $^{46}$.

A compreensão sobre a qualidade de vida de estomizados intestinais é imprescindível no planejamento da assistência de enfermagem para o atendimento das necessidades apresentadas por essa clientela.

O relato de experiência analisado aborda a importância do cuidado especializado do estomizado, além de discutir sobre a organização de uma clínica especializada em estomaterapia e a intervenção do enfermeiro estomaterapeuta na educação pré-operatória e cuidados específicos com estomas, aspectos gerenciais como identificação de necessidades, recursos humanos, ambiente, propaganda da clínica, atendimentos domiciliares oferecidos, freqüência de atendimentos e satisfação do cliente. Estudos deste tipo contribuem para a divulgação sobre as possibilidades e potencialidades do enfermeiro especialista em estomaterapia $^{47}$.

A avaliação dos estomizados acerca da qualidade do cuidado recebido no período perioperatório foi pesquisada em um estudo descritivo exploratório. A assistência de saúde é analisada pela qualidade do cuidado, tratamento médico, cuidado domiciliar, participação e autonomia do paciente, sexualidade e satisfação com a assistência recebida pelo paciente. A maioria dos pacientes mostrou-se satisfeita com o cuidado recebido antes e após a cirurgia $^{48}$. 
Estes estudos são importantes para o estabelecimento de critérios de avaliação sobre o cuidado perioperatório recebido pelo paciente. Fornecem ainda dados fidedignos para investimento, investigações futuras e projetos de melhoria e aperfeiçoamento da assistência de enfermagem prestada aos estomizados.

O estudo teórico em nossa amostra faz uma revisão dos procedimentos cirúrgicos mais comuns, enfatiza o ensino do paciente nos períodos pré e pós-operatórios, as dificuldades encontradas pelos estomizados e a compreensão dos conflitos internos, além de indicações para melhorar o conhecimento de enfermagem, dos pacientes e cuidadores sobre estomias e seus cuidados. Indica a necessidade da estruturação e consistência dos programas de educação permanente aos profissionais para melhorar a prática profissional e o ensino e aconselhamento de pacientes e familiares como estratégias para o alcance da reabilitação pelo estomizado intestinal ${ }^{49}$.

Analisamos também um estudo de caso sobre o cuidado do estomizado obeso. Os autores abordaram a assistência durante todo o período perioperatório. Na fase préoperatória focaram os aspectos físicos, emocionais, demarcação prévia, sistema respiratório e circulatório. Além dos cuidados no trans-operatório com posicionamento e prevenção de lesões de pele, enfatiza os cuidados no pós-operatório como mobilização e monitorização do paciente, prevenção de complicações e lesões de pele e dor. São discutidos aspectos importantes do planejamento da alta incluindo acomodação especial, indicação de equipamentos, acesso aos recursos, motivação e suporte familiar. O estudo aponta os critérios para utilização dos recursos e equipamentos em tempo oportuno para sucesso da terapêutica, diminuição de custos de internação e satisfação do cliente ${ }^{50}$. 
Uma revisão bibliográfica sobre os aspectos envolvidos no cuidado à gestante estomizada foi realizada e identificou as colostomias, ileostomas e urestomas como os tipos de estomas mais freqüentes nas gestantes e descreveu a ocorrência de complicações mais comuns, que podem ser obstrução, prolapso do estoma, hérnia periestoma, sangramento e a retração do estoma. As autoras verificaram ainda, que a grande maioria (69\%) das gestantes realizou parto vaginal e $85 \%$ apresentaram complicações pós-parto. Aspectos como o preparo pré-concepção (explicação sobre possibilidades e riscos); necessidade de cuidado individualizado durante a gestação; com balanço hidroeletrolítico em ileostomizadas com vômitos constante; possíveis complicações com neonatos (pneumonia, aspiração de mecônio, baixo peso e sofrimento fetal); susceptibilidade à infecção urinária; nutrição e controle de odor; constipação; orientações para o cuidado; preparo para o nascimento; terapias complementares e o trabalho multiprofissional foram apresentados na discussão do cuidado especializado de estomizadas gestantes ${ }^{51}$.

A enfermagem é responsável pelos cuidados relacionados com o preparo físico e psicossocial do paciente, ensino e cuidados técnicos, inclusive para pacientes com diferentes necessidades (obesos, crianças e gestantes), com fornecimento de suporte profissional para que o estomizado intestinal alcance a reabilitação. Portanto, trabalhos científicos com pacientes especiais são necessários para possibilitar a assistência holística e especializada.

Alguns pesquisadores investigaram a importância da técnica cirúrgica para a confecção de estomias e cuidados com estomas para a enfermagem. O trabalho indica fontes para busca de conhecimentos (sites), empresas fabricantes de produtos para 
estomizados e alerta que, muitas vezes, o enfermeiro generalista ou cuidador não possui conhecimento apropriado para realizar o cuidado específico com o estoma ${ }^{52}$.

A visão do enfermeiro sobre o cuidado com o estomizado é investigada no estudo qualitativo que identificou como os enfermeiros interpretam o cuidado. O estudo aborda a compreensão do enfermeiro sobre o cuidado do estomizado, sobre a importância do preparo para alta hospitalar e o cuidado proporcionado a essa clientela. As idéias centrais contidas nos dados foram "o paciente precisa de um cuidado especial", "é preciso orientar", "necessidade da enfermagem para orientação" e "reconhecimento das dificuldades para o cuidado especial". O estudo retrata a necessidade de educação permanente para a capacitação dos profissionais de enfermagem envolvidos no atendimento desses pacientes $^{53}$

Vários estudos focalizam estratégias de ensino para o autocuidado com manuseio de equipamentos, adaptação positiva e alcance da reabilitação do estomizado intestinal, como descritos a seguir. Estes trabalhos proporcionam dados para o planejamento do ensino de habilidades e de cuidados aos estomizados e seus familiares, que podem ser utilizados pelos enfermeiros que atuam na prática clínica.

Um estudo qualitativo sobre o processo de implantação e implementação de um grupo de pacientes portadores de estomas intestinais definitivos e identificou a percepção desses quanto à sexualidade. Os principais obstáculos identificados pelo grupo foram: a recusa do parceiro, disfunção erétil, alteração da imagem e o próprio estoma. Os caminhos apontados para satisfação sexual incluíram troca do parceiro, busca de suporte profissional especializado, criatividade no ato sexual e alguns cuidados com o equipamento. A 
experiência de vida de cada integrante permitiu o desenvolvimento da autonomia sexual e fez com que os portadores reconhecessem a necessidade de mantê-la ou buscar auxílio, para o alcance do prazer, satisfação e retorno à vida ${ }^{54}$.

Outro estudo explora as estratégias que o enfermeiro especialista em estomas pode utilizar para que o paciente alcance aprendizado nos períodos pré e pós-operatórios. A autora conclui que o ensino deve ser planejado conforme a prontidão e habilidades do paciente para o aprendizado. Identifica que a comunicação organizada entre o hospital e a comunidade assegura o ensino e suporte assistencial na continuidade e promoção da adaptação positiva e o sucesso na reabilitação ${ }^{55}$.

A experiência de implantação de um website sobre estomias para cuidadores e enfermeiros generalistas é descrita como uma estratégia de educação à distância importante, que contribui no fornecimento de informações e possibilidade de sanar dúvidas, principalmente quando não há possibilidade de acesso ao atendimento especializado ${ }^{56}$.

A descrição e discussão dos problemas que podem ser enfrentados pelos pacientes após a cirurgia e confecção do estoma tais como imagem corporal, aspectos psicológicos, sexualidade e aspectos culturais são abordados em um dos estudos analisados. A autora enfatiza que o ensino do paciente deve considerar todos esses aspectos (técnicos, psicológicos, percepção de imagem corporal e sexualidade) além do preparo do profissional enfermeiro para apropriar a linguagem e comunicação à realidade cultural do paciente e tornar efetivo o tratamento e reabilitação do estomizado.

Os estudos categorizados como Complicações trazem aspectos preventivos e curativos das complicações em estomias intestinais. 
Os quatro estudos analisados nesta categoria são propostas de protocolo. No primeiro estudo são abordados os equipamentos convexos para estomas com retração para prevenção de lesões periestomais. O protocolo aborda a assistência de enfermagem e princípios para indicação e troca de produtos convexos e potenciais fatores de risco associados ao uso destes produtos. Os autores enfatizam que os produtos convexos têm um papel essencial no manejo das dificuldades com estomas retraídos, pois possibilitam protusão. Entretanto, devem ser utilizados apropriadamente e com seguimento e avaliação do enfermeiro, conforme protocolo ${ }^{58}$.

A complicação pós-operatória denominada descolamento muco-cutâneo é discutida no segundo estudo e apresentam um protocolo que aborda as causas do descolamento muco-cutâneo, tipos e gravidade envolvida, além do tratamento efetivo e princípios que promovem ótima cicatrização da ferida. Os autores relacionam a resolução deste problema com possibilidade de adaptação à condição de estomizado e resgate da autoconfiança e auto-estima $^{59}$.

O terceiro estudo propõe um protocolo para demarcação prévia do local do estoma, o que assegura a assistência individualizada e qualidade de vida ao estomizado intestinal, com identificação de problemas que podem influenciar na escolha do local, diminuição das dificuldades para adaptação do sistema coletor e garantir a autonomia do indivíduo. Os autores descrevem os aspectos primordiais na demarcação de estomas: averiguação do conhecimento do paciente sobre a cirurgia; explicação do procedimento; identificação do músculo reto-abdominal, cicatriz umbilical e/ou outras cicatrizes; identificação de proeminências ósseas, pregas de pele, mamas, drenos e feridas e modificações do abdome 
nas posições sentado, em pé e deitado. O estudo enfatiza que a demarcação do estoma é essencial na reabilitação do paciente ${ }^{60}$.

A quarta proposta de protocolo analisada em nossa amostra foi realizada para padronizar a troca do equipamento coletor. $\mathrm{O}$ estudo aborda as características normais da estomia (tamanho, produção e ruídos de funcionamento), descreve a técnica correta para escolha, troca e aplicação dos equipamentos e aponta as causas mais comuns de lesões periestomas $^{61}$.

Com a análise dos estudos categorizados em Cuidados de Enfermagem, Autocuidado e Complicações, pude refletir sobre a assistência de enfermagem do paciente estomizado intestinal, no âmbito hospitalar. As categorias dos estudos analisados trouxeram a possibilidade de fundamentar as etapas importantes no atendimento ao estomizado.

A assistência de enfermagem a esse grupo de pacientes deve ser planejada desde o momento da indicação médica pelo tratamento cirúrgico e da confecção do estoma, durante todo o período de atendimento hospitalar até sua reabilitação física, social e psicológica ${ }^{62}$.

Anterior à internação faz-se necessário uma intervenção do enfermeiro para orientação dos exames pré-operatórios requeridos pelo médico e avaliação do paciente e da dinâmica familiar para identificar necessidades de cuidados. O enfermeiro deverá trabalhar, de forma integrada com os outros profissionais que realizam o seguimento nesta instituição, tais como: assistente social, psicólogo e nutricionista, além do médico. Entretanto, não encontramos estudos científicos que tenham focalizado a assistência de enfermagem a essa clientela, na fase anterior à internação propriamente dita.

No período de internação hospitalar existe a possibilidade de fornecer explicações sobre o planejamento perioperatório do tratamento aos pacientes e familiares, além do 
contato do paciente com outros estomizados, se este assim o desejar. Entretanto não encontramos nenhum estudo que tenha investigado a influência desta estratégia na recuperação do paciente.

Outro aspecto importante na fase pré-operatória é o preparo físico do paciente que inclui alimentação e preparo intestinal para o procedimento cirúrgico. Embora exista a prescrição médica de todos os procedimentos, muitas vezes é da responsabilidade do enfermeiro designar horários das lavagens intestinais. Na prática clínica observamos que não existe um protocolo definido para este procedimento, havendo uma lacuna sobre alguns aspectos como o horário mais apropriado para realização da última lavagem intestinal, os critérios para avaliar a efetividade do procedimento e das soluções indicadas (água e glicerina ou água e bicarbonato de sódio), entre outros.

A realização de estudos clínicos sobre este aspecto poderia fornecer evidência científica para aperfeiçoar a assistência de enfermagem.

Além do preparo intestinal, a demarcação prévia do local do estoma é importante e assegura o autocuidado e previne complicações. A proposta de protocolo resgata conceitos sobre o método utilizado para demarcação e as características individuais que devem ser consideradas $^{60}$.

A demarcação do estoma assegura a qualidade de vida do paciente pois previne complicações pós-operatórias e possibilita a adaptação dos equipamentos coletores ${ }^{41}$.

O próximo passo nesta fase pré-operatória é o ensino. Muitos autores discorrem sobre a importância do planejamento deste ensino. A atividade de ensino do paciente antes e depois da cirurgia é ressaltada incluindo uma explanação sobre o procedimento, exposição e manipulação dos equipamentos (bolsas coletoras e outros equipamentos) antes 
da cirurgia e posteriormente, o ensino da troca do equipamento coletor, bem como os cuidados preventivos e identificação de complicações após a cirurgia ${ }^{49}$.

As estratégias que o enfermeiro especialista em estomas pode utilizar para facilitar o aprendizado em todo o período perioperatório também foram exploradas nos trabalhos analisados. Enfatiza-se a necessidade do planejamento que engloba as peculiaridades individuais do paciente, assim como, a prontidão e habilidades de aprendizado. A autora sugere um modelo de desenvolvimento de recursos humanos e um "checklist" para pontuar todos os passos que deverão ser cumpridos no planejamento de ensino e avaliação do aprendizado. Indica a importância da continuidade do programa de ensino na comunidade após a alta hospitalar para promover com sucesso a reabilitação do paciente ${ }^{55}$.

O impacto do desgaste emocional e físico na qualidade de vida da pessoa com estoma é uma constante em diversos trabalhos científicos e alguns autores sugerem a incorporação da tecnologia para facilitar o ensino e acesso às informações específicas em estomaterapia. A implementação de um website sobre estomias para pacientes, cuidadores e enfermeiros generalistas foi utilizada como uma estratégia de ensino à distância. Os autores sugerem para pesquisa futura a avaliação da aplicação desta estratégia ${ }^{56}$.

As estratégias e indicações de programas de ensino são diversas, contudo não encontramos comprovação científica destas intervenções no aprendizado, diminuição ou redução da ansiedade e recuperação dos pacientes, além das peculiaridades de cada indivíduo que devem ser consideradas para alcance do objetivo das estratégias propostas ${ }^{63}$.

Muito embora existam trabalhos sobre o planejamento da assistência, ainda não temos protocolos de cuidados aos estomizados intestinais no âmbito hospitalar, e as formas 
de integração entre as unidades de saúde (nível de atenção primária, secundária e terciária) para a continuidade do cuidado e seguimento dessa clientela.

Em relação ao período trans-operatório existe uma vasta literatura médica sobre as indicações e técnicas cirúrgicas. Especificamente para a atuação da enfermagem existe a recomendação de acompanhamento do procedimento cirúrgico e padronização do equipamento coletor transparente, de uma peça, logo após o ato cirúrgico. Este dispositivo possibilita a avaliação constante do estoma e seu efluente, além de evitar a compressão abdominal para colocação e retirada do mesmo para higienização ${ }^{5}$.

No pós-operatório imediato a assistência ao paciente deve incluir avaliação da condição geral do paciente, do estoma e efluente, a fim de identificar precocemente complicações como hemorragia, retração, deiscência e necrose.

No decorrer do pós-operatório a assistência de enfermagem objetiva que o paciente retorne gradualmente às suas atividades incluindo o convívio com a sua nova condição, de ser portador de estomia e o aprendizado dos cuidados específicos. A primeira troca pode ser realizada após as 72 horas de cirurgia e deve ser realizada com a participação do paciente, levando-se em consideração o estado geral e disposição do mesmo para o aprendizado ${ }^{41 .}$

A avaliação do estoma (forma, aparência e funcionamento normal), as causas e os problemas mais comuns e o procedimento de troca do equipamento coletor são descritas em uma proposta de protocolo ${ }^{58}$ Os trabalhos que propõe protocolos de assistência sinalizam a preocupação dos pesquisadores na padronização da assistência de enfermagem.

As complicações mais comuns dos estomas podem estar diretamente relacionadas ao aprendizado do paciente/familiar com a assistência prestada ao paciente. As empresas fabricantes de equipamentos destinados a essa clientela têm desenvolvido e divulgados 
amplamente as inovações para o tratamento de complicações. Boyd e cols. (2004) exploram e explicam em seu artigo os objetivos e indicações de produtos convexos.

Outra complicação importante é o descolamento mucocutâneo. Boyd-Carson et al. (2004) - é o mesmo do anterior??? relacionam este com vários fatores da condição geral do paciente e local da estomia como a tensão da pele, a infecção, o desequilíbrio nutricional, as doenças inflamatórias ou a imunossupressão. Propõem limpeza com a irrigação de solução salina (soro fisiológico 0,9\%) morno, recorte adequado da base da bolsa coletora (2-3 $\mathrm{mm}$ de largura maior que o estoma), uso da pasta de resina sintética para favorecer a aderência do equipamento, utilização na área lesionada de coberturas semi-permeáveis e troca do curativo e bolsas de colostomias, mediante necessidade e saturação.

Algumas características apresentadas pelos pacientes requerem maior especialização do cuidado, como por exemplos, as gestantes, as crianças e os pacientes obesos.

Alguns autores desenvolveram um estudo de caso com um paciente obeso durante todo o período perioperatório. No período pré-operatório determinaram a necessidade do preparo físicos e emocional, com ênfase da demarcação estoma e os cuidados prioritários com os sistemas respiratório e cardiovascular do paciente. No intra-operatório enfatizaram a importância do posicionamento adequado, proteção da pele e das áreas de maior compressão. Para o período pós-operatório destacam a necessidade e cuidados na mobilização, inclusive a indicação de equipamentos que favoreçam maior movimentação, a prevenção de úlceras de pressão e deiscência cirúrgica e intervenções para minimizar a dor. Para o planejamento da alta hospitalar inclui-se a acomodação que atenda a necessidade em casa, o acesso aos recursos e programas governamentais e relatam o suporte familiar como um aspecto importante ${ }^{50}$. 
No estudo teórico sobre questões psicológicas, sexuais e culturais dos pacientes com estomas. $\mathrm{O}$ autor descreve alguns dos potenciais problemas que podem ser enfrentados por pacientes após a confecção do estoma. Explora também os problemas sociais e psicológicos relativos à imagem corporal e destaca que os enfermeiros podem auxiliar os pacientes por meio do encorajamento para expor sentimentos e experiências relacionadas aos aspectos sexuais, culturais e psicológicos ${ }^{57}$.

O profissional enfermeiro deve atentar para aspectos culturais e não julgamento do paciente, atuando com comunicação adequada para tratamento efetivo e reabilitação do paciente e quando identificar sintomas significativos de ansiedade ou depressão, indicar ao paciente acompanhamento psicológico.

No planejamento da alta hospitalar além do encaminhamento do paciente ao Programa dos Ostomizados (mantido pelo Sistema Único de Saúde), é possível apresentar as outras possibilidades de recursos, ensino do autocuidado e indicação do equipamento mais adequado à necessidade do paciente.

A irrigação intestinal é um recurso utilizado com objetivo de possibilitar a continência intestinal aos pacientes com estomias, confeccionadas na porção do intestino grosso. O treinamento é de responsabilidade do enfermeiro estoma-terapeuta ou enfermeiro capacitado para realizar tal procedimento ${ }^{41}$.

O estudo teórico sobre estomias concluiu que muitas vezes o enfermeiro generalista ou o cuidador não possui conhecimento apropriado sobre cuidados com estomas e indica os websites do Conselho Internacional de Estomas, Feridas e Incontinências (WOCN) e empresas especializadas em desenvolvimento de produtos para estomaterapia como fonte de pesquisa e obtenção de conhecimento ${ }^{52}$. 
Os estudos da prática baseada em evidências podem contribuir para o aperfeiçoamento da prática clínica dos enfermeiros no planejamento do cuidado hospitalar aos estomizados intestinais.

Dentre todos os aspectos descritos neste capítulo, acreditamos que o essencial para melhorar qualidade da assistência de enfermagem hospitalar aos estomizados intestinais seja o conhecimento, a conscientização e a sensibilização do profissional de enfermagem.

O enfermeiro perioperatório necessita de possibilidades organizacionais, tanto de recursos como tempo para realizar pesquisas na busca de melhores evidências para viabilizar mudanças na assistência aos pacientes ${ }^{24}$.

Acreditamos que a capacitação dos enfermeiros generalistas na área específica de estomaterapia e a inclusão desse tema em programas de educação permanente podem assegurar maior qualidade na assistência aos estomizados intestinais.

Outra lacuna é o estudo sobre o impacto da atuação dos enfermeiros estomaterapeutas em programas de atendimento das empresas privadas de equipamentos para estomizados. Não encontramos também estatísticas sobre as possibilidades no mercado de trabalho e da inserção dos enfermeiros estomaterapeutas nas instituições hospitalares.

A enfermagem carece ainda, de trabalhos específicos na área de assistência de enfermagem hospitalar ao estomizado intestinal, que possam fornecer forte evidência científica para prática clínica. Investimentos devem ser realizados para preparar melhor os enfermeiros para participar em pesquisas, tanto para elaborar e conduzir estudos que possibilitem a tomada de decisões mediante conhecimento científico. 


\section{CONSIDERAÇÕES FINAIS}

O desenvolvimento deste trabalho possibilitou dimensionar e analisar a produção do conhecimento sobre a assistência de enfermagem hospitalar ao estomizado intestinal.

Do total de vinte e dois $(100 \%)$ trabalhos, tivemos dezoito $(81,8 \%)$ produzidos por dois ou mais autores, sendo a primeira autoria de vinte $(90,4 \%)$ enfermeiros, um $(4,5 \%)$ supervisor de ensino e um $(4,5 \%)$ aluno de graduação; oito $(36,3 \%)$ autores atuavam em universidades, sete $(31,8 \%)$ em instituições hospitalares e sete $(31,8 \%)$ não citavam o local de atuação profissional.

A análise destes dezoito (100\%) trabalhos em relação a segunda autoria, obtivemos um envolvimento de dezesseis $(88,8 \%)$ enfermeiros, um $(5,5 \%)$ pedagoga e um $(5,5 \%)$ não constava a profissão; destes, cinco $(27,7 \%)$ autores pertenciam às instituições hospitalares, oito $(36,3 \%)$ às universidades e cinco $(27,7 \%)$ não citavam o local de trabalho.

Identificamos nove $(40,9 \%)$ trabalhos científicos de prodição brasileira, oito $(36,3 \%)$ produzidos na Inglaterra, sete $(31,8 \%)$ nos Estados Unidos e um $(4,5 \%)$ na Escócia.

O tipo de publicação predominante foi em forma de artigo científico com dezessete $(77,2 \%)$ trabalhos, três $(13,6 \%)$ na forma de dissertação de Mestrado e um $(4,5 \%)$ tese de Doutorado.

Os periódicos de publicação destes trabalhos foram diversos. Identificamos quatro $(18,2 \%)$ publicações no periódico Nursing Standard, três $(13,6 \%)$ no British Journal Nursing, três $(13,6 \%)$ no Ostomy Manage Nursing, dois $(9,1 \%)$ na Revista Latino Americana de Enfermagem (Ribeirão Preto), um (4,5\%) no Complement Ther Nurs Midwifery, um (4,5\%) no Gastroenterology Nursing, um (4,5\%) na revista Nursing (São 
Paulo), um (4,5\%) na Revista Brasileira de Cancerologia (Rio de Janeiro), um (4,5\%) na RN, 04 (18,2\%) teses e dissertações oriundos dos cursos de pós-graduação da Universidade de São Paulo (USP) e um (4,5\%) no Simpósio Internacional de Iniciação Científica da Universidade de São Paulo (SIICUSP). Isso representa um aspecto positivo, pois mostra uma amplitude de possibilidades de publicação sobre o tema.

Dos vinte e dois trabalhos científicos, o delineamento científico é majoritariamente caracterizado por estudos teóricos, totalizando nove (41\%) trabalhos da amostra. Na abordagem qualitativa obtivemos três $(13,7 \%)$ trabalhos científicos que utilizaram o método etnográfico, um $(4,5 \%)$ estudo de caso e uma $(4,5 \%)$ pesquisa participante; e na abordagem quantitativa localizamos três $(13,7 \%)$ trabalhos com método descritivo exploratório e um $(4,5 \%)$ retrospectivo descritivo.

Com a análise dos métodos utilizados nos trabalhos sobre a assistência de enfermagem hospitalar ao estomizado intestinal, concluímos que ainda não identificamos trabalhos com nível forte de evidência para realizarmos revisões sistemáticas sobre determinada intervenção ou procedimento clínico.

Dos vinte e dois (100\%) estudos incluídos nesta revisão integrativa, catorze $(63,6 \%)$ trabalhos científicos foram categorizados em Cuidados de Enfermagem, quatro (18,2\%), em Autocuidado e quatro (18,2\%) em Complicações.

Na categoria Cuidados de Enfermagem, o enfoque é assistência de enfermagem no período perioperatório, principalmente o planejamento de cuidados ao estomizado intestinal, além de aspectos conceituais técnicos, sob a perspectiva do paciente e/ou do familiar e do profissional. 
Os estudos categorizados como Autocuidado exploram as situações clínicas e estratégias de ensino do autocuidado e aspectos como sexualidade e imagem corporal do estomizado intestinal.

$\mathrm{Na}$ categoria Complicações, os estudos abordam aspectos de prevenção e tratamento das complicações dos estomas intestinais, assim como apresentam aspectos mais especializados do cuidado como demarcação prévia do estoma, avaliação do estoma, troca do equipamento coletor e resoluções de complicações.

Identificamos estudos desenvolvidos por especialistas, com base teórica científica e que propõem protocolos clínicos para o cuidado hospitalar do estomizado, porém não constituem metodologicamente estudos clínicos.

O intuito da realização de pesquisas científicas é assegurar a melhora da qualidade da prática clínica de enfermagem e consequentemente da qualidade de vida dos estomizados intestinais.

Os desafios para futuras pesquisas estão relacionados à busca de evidências científicas acerca da assistência prestada durante o período de internação hospitalar e aos aspectos especializados como indicação de equipamentos, desenvolvimentos de protocolos, escolha de métodos de ensino e influência destes no aprendizado e na vida destes pacientes.

A utilização da revisão integrativa contribuiu para o alcance dos objetivos propostos neste trabalho. 


\section{REFERÊNCIAS}

[1] Polit DF, Beck CT, Hungler BP. Fundamentos de Pesquisa em Enfermagem: métodos, avaliação e utilização. Porto Alegre: Artmed; 2004.

[2] Joviliano OFD. In Coloproctologia - Rocha JJR da. Coloproctologia: princípios e práticas. São Paulo:Atheneu; 2005. p.7-13.

[3] Rocha JJR, Jr AM. Estomas Intestinais. In. Rocha JJR da. Coloproctologia: princípios e práticas. São Paulo:Atheneu; 2005 p. 111-18.

[4] Keighley MRB, Williams NS. Surgery of the anus, rectum and colon. London: W.B.Saunders Company; 1993. p.139-201.

[5] Santos VLCG, Cesaretti IUR Assistência em estomaterapia: cuidando do ostomizado.São Paulo: Atheneu; 2000.

[6] Cesaretti IUR, Paula MAB de, Paula PR. Estomaterapia: temas básicos em estomas. Taubaté SP: Cabral Editora e Livraria Universitária; 2006.

[7] Santos VLCG, Cesaretti IUR. Assistência em estomaterapia: cuidando do ostomizado.São Paulo: Atheneu, 2000.

[8] Sonobe HM, Barichello E, Zago MMF. A visão do colostomizado sobre o uso da bolsa de colostomia. Revista Brasileira de Cancerologia (Rio de Janeiro) 2002;48 (3): p.341-348.

[9] Persson E, Hellstrõm AL. Experiences of Swedish Men and Women 6 to 12 weeks after ostomy surgery. WOCN Journal, 2002; 29(2):103-108.

[10] Meirelles CA. Avaliação de resultados dos processos de demarcação do estoma intestinal e de orientações para o autocuidado [Dissertação]. São Paulo: Escola de Enfermagem de Ribeirão preto, Universidade de São Paulo; 2000.

[11] Pellicia R, Moritaka L, Paegle LD, Roncaratti E, Pisetta V, Sassaki MM et al. Sistematização da assistência de enfermagem ao colostomizado ileostomizado em um hospital privado.Rev Pul Enferm (São Paulo), 1992; 11(1): 41-5. 
[12] Benedini Z. Pesquisando para educar: a "pedagogia do ostomizado" e a prática da visita domiciliária. [Tese]. São Paulo: Escola de Enfermagem de Ribeirão Preto, Universidade de São Paulo;1993.

[13] Tostes ECP. Dificuldades que interferem na assistência ao paciente ileostomizado ou colostomizado: um estudo de enfermagem. Rio de Janeiro;1980. 99p.

[14] Wong VK, White MA. Family dynamics and helath lócus of control in adults with ostomies. WOCN Journal. 2002; 29 (1):37-44.

[15] Shoothil K, Morris SM; Thomas C, Harman JC, Francis B, Mclllmurray MB. The universal, situational and personal needs of cancer patients and their mains carers. European Journal of Oncology Nursing 2003; 7 (1):5-13.

[16] Poggetto MTD. Temáticas de aprendizagem de clientes colostomizados. [Dissertação]. Ribeirão Preto: Escola de Enfermagem de Ribeirão Preto da Universidade de São Paulo. 2002.

[17] Petuco VM. A bolsa ou a morte: estratégias de enfrentamento utilizadas pelos ostomizados de Passo Fundo/RS.[Dissertação]. São Paulo: Faculdade de Saúde Pública, Universidade de São Paulo, São Paulo, 1998.

[18] Santos VLC. A bolsa na mediação "estar ostomizado" - "estar profissional”: análise de uma estratégia pedagógica.[Tese]. São Paulo: Escola de Enfermagem da Universidade de São Paulo; 1996.

[19] Gemelli LMG, Zago MMF. A interpretação do cuidado com o ostomizado na visão do enfermeiro: um estudo de caso. Revista Latino Americana de Enfermagem (Ribeirão Preto).2002; 10 (1): 34-40.

[20] Maruyama SAT. A experiência da colostomia por câncer como ruptura biográfica na visão dos portadores, familiares e profissionais de saúde: um estudo etnográfico.[Tese]. Ribeirão Preto: Escola de Enfermagem de Ribeirão Preto, Universidade de São Paulo; 2004.

[21] Martelli ZB. Necessidades de aprendizagem da pessoa colostomizada: impressão diagnóstica do enfermeiro, através da observação militante e taxonomia de objetivos 
educacionais.[Dissertação]. Ribeirão Preto: Escola de Enfermagem de Ribeirão Preto, Universidade de São Paulo;1983.

[22] Caliri MHL. A utilização da pesquisa na prática clínica da enfermagem: limites e possibilidades. [Livre Docência]. Ribeirão Preto: Escola de Enfermagem de Ribeirão Preto, Universidade de São Paulo; 2002.

[23] Hamer S. Evidence-based practice. In: Hamer S, Collinson G. Achieving evidencebased practice: a handbook for practioners. London:Balliere Tindall; 1999. p.3-12.

[24] Galvão CM, Sawada NO, Trevizan MA. Revisão Sistemática: recurso que proporciona a incorporação da evidência na prática de enfermagem. Revista Latino-Americana (Ribeirão Preto) 2004; 12(3):549-556.

[25] Ursi ES. Prevenção de lesões de pele no perioperatório:revisão integrativa da literatura. [Dissertação]. Ribeirão Preto: Escola de Enfermagem de Ribeirão Preto, Universidade de São Paulo; 2005.

[26] Santana ME. Fístula faringocutânea após laringectomia total: revisão sistemática e implicações para enfermagem. [Tese]. Ribeirão Preto: Escola de Enfermagem de Ribeirão Preto, Universidade de São Paulo; 2004.

[27] Galvão CM. A prática baseada em evidências: uma contribuição para a melhoria da assistência de enfermagem perioperatória. [Livre Docência]. Ribeirão Preto: Escola de Enfermagem de Ribeirão Preto, Universidade de São Paulo; 2002.

[28] Closs SJ, Cheater FM. Evidence for nursing practice: a clarification of the issues. J. Adv. Nursing. 1999; 30(1):10-17.

[29] Evans D, Pearson A. Systematic reviews of qualitative research. Clinical Effectiveness in Nursing. Australia. 2001; 5:111-119.

[30] Burns N, Grove SK. The evolution of research in nursing. In: The practice of nursing research of nursing research: conduct, critique and utilization. Philadelphia: W.B. Saunders Company; 2001c.;p.37-60. 
[31] Broome ME. Integrative literature reviews in the development of concepts. In: Rodgers BL, Knafl KA. Concept development in nursing: foundations, techniques and applications. Philadelphia:W.B. Saunders Company; 1993.p.193-215.

[32] Stetler CB, Morsi, D, Rucki S, Broughton S, Corrigan B, Fitzgerald J, et al. Utilization - focused integrative reviews in a nursing service. Applied Nursing Research. 1998; 11(4): 195-206.

[33] Beya SC, Nicoll LH. Writing an integrative review. AORN J. 1998; 67(4):877-880.

[34] Fernandes LM. Úlcera de pressão em pacientes críticos hospitalizados: uma revisão integrativa de literatura. [Dissertação]. Ribeirão Preto: Escola de Enfermagem de Ribeirão Preto, Universidade de São Paulo;2000.

[35] Silveira CS. A pesquisa em enfermagem oncológica no Brasil: uma revisão integrativa [Mestrado]. Ribeirão Preto: Escola de Enfermagem de Ribeirão Preto, Universidade de São Paulo; 2005.

[36] Ganong LH. Integrative reviews of nursing research. Research in Nursing \& Health. $1987 ; 10(1): 1-11$.

[37] Campos RG. Burnout: Uma revisão integrativa na enfermagem oncológica. [Dissertação]. Ribeirão Preto: Escola de Enfermagem de Ribeirão Preto, Universidade de São Paulo; 2005.

[38] Polit DF, Beck CT, Hungler BP. Fundamentos de pesquisa em enfermagem: método, avaliação e utilização. $5^{\mathrm{a}}$.ed. Porto Alegre: Artmed Editora; 2004.

[39] Lobiondo G, Haber J. Pesquisa em enfermagem, métodos, avaliação crítica e utilização. 4a .ed. Rio de Janeiro: Guanabara Koogan; 2001.

[40] Poggetto MTD. Temáticas de aprendizagem de clientes colostomizados.[Mestrado].Ribeirão Preto: Escola de Enfermagem de Ribeirão Preto, Universidade de São Paulo; 2002.

[41] Drummond JP, Silva E. Medicina baseada em evidências: novo paradigma assistencial e pedagógico. São Paulo: Atheneu Editora; 1999. 
[42] Borges EL, Carvalho DV. Portador de estoma gastrointestinal: perfil de uma clientela. Nursing (São Paulo) 2002; 5(46):15-21.

[43] Bezerra IM, Sonobe HM. Análise de literatura sobre registro de enfermagem com colostomizados. Simpósio Internacional de Iniciação Científica da Universidade de São Paulo (Ribeirão Preto).2002; v.2:111.

[44] Maruyama SAT. A experiência da colostomia por câncer como ruptura biográfica na visão dos portadores, familiares e profissionais de saúde: um estudo etnográfico. [Tese]. Ribeirão Preto: Escola de Enfermagem de Ribeirão Preto, Universidade de São Paulo; 2004.

[45] Maruyama SAT. O processo de adoecer do portador de colostomia por câncer. Revista Latino-Americana de Enfermagem. (Ribeirão Preto).2005;13(2):216-222.

[46] Kameo SY. Qualidade de vida do paciente com estoma intestinal secundária ao câncer cólon-retal. [Dissertação]. Ribeirão Preto: Escola de Enfermagem de Ribeirão Preto, Universidade de São Paulo; 2006.

[47] Fliescher I, Bryant D. Prescription for excellence: na osotmy clinic.Ostomy Wound Manage.2005;51(9):32-8.

[48] Persson E, Wilde Larsson B. Quality of care after ostomy surgery: a perspective study of patients. Ostomy Wound Manage. 2005; 51(8): 40-8.

[49] Ringhofer J. Meeting the needs of your ostomy patient. RN.2005; 68(8):37-41.

[50] Gallagher S, Gates J. Challenges of ostomy care and obesity. Ostomy Wound Manage. 2004; 50 (9): 38-40.

[51] Aukamp V, Sredl D. Collaborative care management for a pregnant woman with an ostomy. Complement Ther Nurs Midwifery.2004;10(1): 5-12.

[52] Hyland J. The basics of ostomies. Gastroenterol Nurs. 2002; 25(6); 241-4.

[53] Gemelli LMG, Zago MMF. A interpretação do cuidado com o ostomizado na visão do enfermeiro: um estudo de caso. Revista Latino Americana de Enfermagem. 2002; 10(1): $34-40$. 
[54] Pereira, APS. Educação sexual de grupos de adultos portadores de estomas intestinais definitivos: processo da implantação e implementação. [Dissertação]. Ribeirão Preto: Escola de Enfermagem de Ribeirão Preto, Universidade de São Paulo; 2006.

[55] O'Connor G. Teaching stoma-management skills: the importance of self-care. British Journal Nursing. 2005; 14 (6): 320-4.

[56] Hollinworth H, Howlett S, Tallett J, Pettitt S, Cooper D, Skingley S, Power S, Woolgar A, Fendley C. Professional holistic care of the person with a stoma: online learning. British Journal Nursing. 2004; 13(21): 1268-75.

[57] Black PK. Psychological, sexual and cultural issues for patients with a stoma. Bristish Journal Nursing. 2004; 13 (12): 692-7.

[58] Boyd K, Thompson MJ; Boyd-Carson W; Trainor B. Use of convex appliances. Nursins Standard. 2004; 18(20); 37-8.

[59] Boyd-Carson W, Thompson MJ, Trainor B, Boyd K. Mucocutaneous separation. Nursing Standard. 2004; 18(17): 41-3.

[60] Rutledge M, Thompson MJ, Boyd-Carson W. Effective stoma siting. Nursing Standard. 2003; 18(12): 43-4.

[61] Trainor B, Thompson MJ, Boyd-Carson W, Boyd K. Changing an appliance. Nursing Standard. 2003; 18(13): 41-2.

[62] Santos VLCG, Cesaretti IUR. Assistência em estomaterapia:cuidando do ostomizado.São Paulo: Atheneu; 2000.

[63] Poggetto MTD. Temáticas de aprendizagem de clientes colostomizados.[Mestrado].Ribeirão Preto: Escola de Enfermagem de Ribeirão Preto, Universidade de São Paulo; 2002. 


\section{APÊNDICE}

8.1. Apêndice A

Estudos incluídos na categoria Cuidados de Enfermagem. Ribeirão Preto - São Paulo, 2007.

\begin{tabular}{|c|c|c|c|c|c|}
\hline $\mathrm{N}^{\mathbf{0}}$ & AUTOR & ANO & TÍTULO & ASPECTOS ABORDADOS & CONCLUSÕES \\
\hline 01 & $\begin{array}{l}\text { Fleischer, I; } \\
\text { Bryant, D }\end{array}$ & 2005 & $\begin{array}{l}\text { Feature: Prescription for excellence: } \\
\text { an ostomy clinic }\end{array}$ & $\begin{array}{l}\text { - Educação pré-operatória e cuidados com estoma } \\
\text {-Clínica especializada: aspectos (necessidades, } \\
\text { recursos humanos e ambiente) } \\
\text { - Marketing e propaganda } \\
\text { - Tipos de visita / freqüência de atendimento } \\
\text { - Satisfação do cliente }\end{array}$ & $\begin{array}{l}\text {-Importância do serviço } \\
\text { especializado ambulatorial } \\
\text { - Aumento da qualidade de vida } \\
\text { dos pacientes } \\
\text { - Melhora da adaptação ao estoma } \\
\text { e integração social. }\end{array}$ \\
\hline 02 & $\begin{array}{l}\text { Persson, E; } \\
\text { Wilde } \\
\text { Larsson,B }\end{array}$ & 2005 & $\begin{array}{c}\text { Feature:Quality of care after ostomy } \\
\text { surgery: a perspective study of } \\
\text { patients }\end{array}$ & $\begin{array}{l}\text { - Dados demográficos } \\
\text { - Qualidade do cuidado } \\
\text { - Tratamento médico } \\
\text { - Cuidado domiciliar } \\
\text { - Participação / Sexualidade } \\
\text { - Satisfação com cuidado recebido }\end{array}$ & $\begin{array}{l}\text { - A maioria dos pacientes } \\
\text { mostrou-se satisfeito com o } \\
\text { cuidado recebido antes e após a } \\
\text { cirurgia.. }\end{array}$ \\
\hline 03 & Ringhofer, J & 2005 & $\begin{array}{c}\text { Meeting the needs of your ostomy } \\
\text { patient }\end{array}$ & $\begin{array}{l}\text {-Revisão dos procedimentos cirúrgicos mais comuns } \\
\text { - Importância do ensino do paciente antes e após a } \\
\text { cirurgia } \\
\text { - Dificuldades enfrentadas pelos pacientes } \\
\text {-Compreensão dos conflitos internos dos pacientes. }\end{array}$ & $\begin{array}{l}\text { - Indicações de fontes de } \\
\text { informações para melhorar a } \\
\text { assistência de enfermagem e o } \\
\text { conhecimento dos próprios } \\
\text { pacientes. } \\
\text { - O programa de ensino e } \\
\text { aconselhamento estruturado e } \\
\text { consistente é um aspecto crítico } \\
\text { para reabilitação do paciente. }\end{array}$ \\
\hline
\end{tabular}




\begin{tabular}{|c|c|c|c|c|c|}
\hline 06 & $\begin{array}{l}\text { Gallagher } \\
\text { S; Gates J }\end{array}$ & 2004 & $\begin{array}{c}\text { Feature: Challenges of ostomy care } \\
\text { and obesity }\end{array}$ & $\begin{array}{l}\text { - Preparo pré-operatório (físico, emocional, } \\
\text { demarcação, sistema cárdio-respiratório) } \\
\text { - Intra-operatório } \\
\text { - Pós-operatório (cuidados com a mobilização, } \\
\text { prevenção de complicações e úlceras de pressão, } \\
\text { deiscência, dor) } \\
\text { - Planejamento da alta (acomodação especial, } \\
\text { equipamentos, acesso á recursos, motivação e } \\
\text { suporte familiar) }\end{array}$ & $\begin{array}{l}\text {-Uso de recursos em tempo } \\
\text { oportuno e o uso apropriado de } \\
\text { equipamentos } \\
\text {-Avaliação da relação } \\
\text { terapêuticaxcustox satisfação tem } \\
\text { que ser considerada. }\end{array}$ \\
\hline 13 & Hyland J & 2003 & The basics os ostomies & $\begin{array}{l}\text { - Cuidados com estomas } \\
\text { - Colostomias/Ileestomas/Urestomas/ } \\
\text { - Fístulas mucosa } \\
\text { - Sutura do estoma } \\
\text { - Necessidades nutricionais } \\
\text {-Intervenções de enfermagem na endoscopia }\end{array}$ & $\begin{array}{l}\text { - Muitas vezes o enfermeiro } \\
\text { generalista ou o cuidador não possui } \\
\text { conhecimento apropriado sobre } \\
\text { cuidados com o estoma. } \\
\text { - Indicação de fontes para busca do } \\
\text { conhecimento ou empresas que } \\
\text { trabalham com produtos para } \\
\text { estomizados }\end{array}$ \\
\hline 14 & $\begin{array}{l}\text { Gemelli } \\
\text { LM; Zago } \\
\text { MM }\end{array}$ & 2002 & $\begin{array}{l}\text { A interpretação do cuidado com o } \\
\text { ostomizado na visão do enfermeiro: } \\
\text { um estudo de caso }\end{array}$ & $\begin{array}{l}\text { - A visão do enfermeiro acerca do cuidado do } \\
\text { ostomizado } \\
\text { - Aspectos importantes para o preparo do paciente } \\
\text { para alta hospitalar } \\
\text { - O cuidado ao estomizado intestinal }\end{array}$ & $\begin{array}{l}\text { Idéias Centrais } \\
\text {-O paciente precisa de um cuidado } \\
\text { especial } \\
\text { - É preciso orientar } \\
\text { - Necessidades da enfermagem para } \\
\text { orientação } \\
\text { - Necessidade de educação } \\
\text { continuada efetiva e atuante. } \\
\text { - Necessidade de atividades } \\
\text { científicas que possam contribuir } \\
\text { com a capacitação de recursos } \\
\text { humanos. }\end{array}$ \\
\hline
\end{tabular}




\begin{tabular}{|c|c|c|c|c|c|}
\hline 15 & $\begin{array}{l}\text { Borges, } \\
\text { Eline Lima; } \\
\text { Carvalho, } \\
\text { Daclé } \\
\text { Vilma }\end{array}$ & 2002 & $\begin{array}{l}\text { Portador de estoma gastrointestina: } \\
\text { perfil de uma clientela }\end{array}$ & $\begin{array}{l}\text { - Identificação; dados clínicos; exame físico } \\
\text { - Avaliação da pele periestoma } \\
\text { - Aspecto do efluente } \\
\text { - Autocuidado }\end{array}$ & $\begin{array}{l}\text { Principais: } \\
\text { - Estoma: } 80 \% \text { de eliminação e } 20 \% \\
\text { de alimentação } \\
\text { - Permanência: } 80 \% \text { temporário } \\
\text { - Complicações: } 65 \% \\
\text { - Dispositivo: } 37,5 \% \text { não usavam ou } \\
\text { era inadequado } \\
\text { - Orientações devem iniciar no pré- } \\
\text { operatório } \\
\text { - A convivência com outros } \\
\text { estomizados } \\
\text { - Necessidade de atendimento } \\
\text { multiprofissional aos familiares. }\end{array}$ \\
\hline 16 & $\begin{array}{l}\text { Sonobe, } \\
\text { Helena } \\
\text { Megumi }\end{array}$ & 2002 & $\begin{array}{c}\text { A visão do colostomizado sobre o uso } \\
\text { da bolsa de colostomia }\end{array}$ & $\begin{array}{l}\text { - Reconhecimento das limitações e mudanças } \\
\text { ocorridas. } \\
\text { - As possibilidades após o uso da bolsa de } \\
\text { colostomia. }\end{array}$ & $\begin{array}{l}\text { - O paciente necessita viver seu } \\
\text { momento de luto, de perdas, para } \\
\text { encontrar forças para aceitar e } \\
\text { trabalhar as suas perspectivas. } \\
\text { - A resolução das dificuldades } \\
\text { depende dos recursos internos e do } \\
\text { suporte social fornecido pela } \\
\text { família, pelos profissionais e } \\
\text { estrutura de atendimento oferecida. }\end{array}$ \\
\hline 17 & $\begin{array}{l}\text { Poggetto, } \\
\text { Márcia } \\
\text { Tasso Dal }\end{array}$ & 2002 & $\begin{array}{l}\text { Temáticas de aprendizagem de } \\
\text { clientes colostomizados:estratégias } \\
\text { norteadoras da assistência de } \\
\text { enfermagem. }\end{array}$ & $\begin{array}{l}\text { - Mudanças físicas } \\
\text { - Mudanças psico-sociais } \\
\text { - Conquistas nesse percurso }\end{array}$ & $\begin{array}{l}\text {-A atividade educativa do } \\
\text { enfermeiro deve favorecer a } \\
\text { conscientização da situação que } \\
\text { estão vivenciando, a reconhecer a } \\
\text { necessidade do desenvolvimento de } \\
\text { capacidades e habilidades para o } \\
\text { autocuidado, garantindo a sua } \\
\text { independência e autonomia. }\end{array}$ \\
\hline 18 & $\begin{array}{l}\text { Bezerra, Isa } \\
\text { Menezes }\end{array}$ & 2002 & $\begin{array}{l}\text { Análise de literatura sobre registros de } \\
\text { enfermagem com colostomizados }\end{array}$ & -Identificação dos trabalhos sobre colostomizados & $\begin{array}{l}\text { - Atualização e definição de temas } \\
\text { para pesquisa. } \\
\text { - Inexistência de trabalhos } \\
\text { específicos sobre registro de } \\
\text { enfermagem para o colostomizado. }\end{array}$ \\
\hline
\end{tabular}




\begin{tabular}{|c|c|c|c|c|c|}
\hline 19 & $\begin{array}{l}\text { Maruyama, } \\
\text { Sônia } \\
\text { Ayako Tao }\end{array}$ & 2004 & $\begin{array}{l}\text { A experiência da colostomia por } \\
\text { câncer como ruptura biográfica na } \\
\text { visão dos portadores, familiares e } \\
\text { profissionais de saúde:um estudo } \\
\text { etnográfico. }\end{array}$ & $\begin{array}{l}\text { - A vida antes da colostomia por câncer } \\
\text { - O processo de adoecer } \\
\text { - O cuidado profissional ao portador de colostomia por } \\
\text { câncer e seu familiar. }\end{array}$ & $\begin{array}{l}\text { - O estudo possibilitou } \\
\text { compreender que o destino, o } \\
\text { sofrimento e a individualidade se } \\
\text { integram de forma lógica no } \\
\text { fenômeno como uma ruptura } \\
\text { biográfica, na visão dos sujeitos, } \\
\text { que deve ser considerada pelos } \\
\text { profissionais. }\end{array}$ \\
\hline 20 & $\begin{array}{l}\text { Maruyama, } \\
\text { Sônia } \\
\text { Ayako Tao }\end{array}$ & 2005 & $\begin{array}{l}\text { O processo de adoecer do portador de } \\
\text { colostomia por câncer }\end{array}$ & - A vida antes da colostomia por câncer & $\begin{array}{l}\text { - A experiência de ter uma } \\
\text { colostomia por câncer é uma } \\
\text { construção sociocultural. }\end{array}$ \\
\hline 21 & $\begin{array}{l}\text { Kameo, } \\
\text { Simone } \\
\text { Yuriko }\end{array}$ & 2006 & $\begin{array}{l}\text { Qualidade de vida do paciente com } \\
\text { estoma intestinal secundária ao câncer } \\
\text { cólon-retal }\end{array}$ & $\begin{array}{l}\text { - Características sócio-demográficas } \\
\text { - Localização do tumor } \\
\text { - Tipo de estoma } \\
\text { - Qualidade de vida }\end{array}$ & $\begin{array}{l}\text {-Pacientes com menos de um ano } \\
\text { de estoma apresentam maior } \\
\text { atividade social do que aqueles } \\
\text { com mais de um ano de estoma } \\
\text { - Função física teve maior média } \\
\text { entre pessoas casadas. } \\
\text { - Presença da dor foi maior entre } \\
\text { o grupo de pessoas viúvas e } \\
\text { separadas } \\
\text { - Escala estado geral de saúde m } \\
\text { estatisticamente significativos, o } \\
\text { sexo e complicações, com médias } \\
\text { superiores entre aqueles do sexo } \\
\text { masculino e com presença de } \\
\text { complicações. } \\
\text { - Sintoma dispnéia: maior média } \\
\text { entre aqueles com metástase } \\
\text { - As escalas função emocional, } \\
\text { dispnéia, dificuldade financeira e } \\
\text { estado geral de saúde tiveram } \\
\text { influência das variáveis sexo, } \\
\text { estado civil, estado de } \\
\text { procedência, metástase, tempo de } \\
\text { estoma e complicações. }\end{array}$ \\
\hline
\end{tabular}




\begin{tabular}{|c|c|c|c|c|c|}
\hline 09 & $\begin{array}{l}\text { Aukamp } \\
\text { V; Sredl D }\end{array}$ & 2004 & $\begin{array}{l}\text { Collaborative care management for a } \\
\text { pregnant woman with na ostomy }\end{array}$ & $\begin{array}{l}\text { - Tipos de estomias mais freqüentes na gravidez } \\
\text { - Complicações durante a gestação e pós-parto } \\
\text {-Complicações com neonatos } \\
\text { - Considerações e preparo pré-concepção } \\
\text { - Cuidado Individualizado durante a gestação } \\
\text { - Balanço hidroeletrolítico com vômitos e ileestoma } \\
\text { - Nutrição e controle de odor } \\
\text { - Constipação e risco de obstrução } \\
\text {-Orientações de autocuidado } \\
\text { - Preparo para o nascimento } \\
\text {-Trabalho multiprofissional. }\end{array}$ & $\begin{array}{l}\text { - A importância do conhecimento } \\
\text { específico e preparo do enfermeiro } \\
\text { pata coordenação do cuidado e ensino } \\
\text { para cliente e família. }\end{array}$ \\
\hline
\end{tabular}


Estudos incluídos na categoria Autocuidado Ribeirão Preto - São Paulo, 2007.

\begin{tabular}{|c|c|c|c|c|c|}
\hline $\mathbf{N}^{\mathbf{o}}$ & AUTOR & ANO & TÍTULO & ASPECTOS ABORDADOS & CONCLUSÕES \\
\hline 04 & $\mathrm{O}^{\prime}$ Connor $\mathrm{G}$ & 2005 & $\begin{array}{l}\text { Teaching stoma- } \\
\text { management } \\
\text { skills: the } \\
\text { importance of } \\
\text { self-care }\end{array}$ & $\begin{array}{l}\text { - Ensino pré-operatório } \\
\text { - Avaliação / Admissão no hospital } \\
\text { - Ensino pós-operatório / } \\
\text { Planejamento do ensino } \\
\text { - Operacionalização do programa } \\
\text { de ensino } \\
\text { - Experiência de aprendizado }\end{array}$ & $\begin{array}{l}\text { - O programa de ensino deve abordar o paciente desde a internação pré- } \\
\text { operatória até a alta hospitalar. É importante que o programa de ensino } \\
\text { tenha continuidade na comunidade após a alta hospitalar para promover } \\
\text { ajuste positivo e facilitar o sucesso na reabilitação. }\end{array}$ \\
\hline 05 & $\begin{array}{l}\text { Hollinworth } \\
\text { H; Howlett } \\
\text { S; Tallett J; } \\
\text { Pettitt S; } \\
\text { Cooper D; } \\
\text { Skingley S; } \\
\text { Power S; } \\
\text { Woolgar A; } \\
\text { Fendley C } \\
\end{array}$ & 2004 & $\begin{array}{l}\text { Professional } \\
\text { holistic care of } \\
\text { the person with a } \\
\text { stoma: online } \\
\text { learning }\end{array}$ & $\begin{array}{l}\text { - Ensino do autocuidado } \\
\text { - Complicações } \\
\text { - Adaptação à estomia (sexualidade } \\
\text { e imagem corporal) }\end{array}$ & $\begin{array}{l}\text { - O desgaste emocional e físico da pessoa com estoma tem grande } \\
\text { impacto em sua qualidade de vida. } \\
\text { - A implementação de um site específico sobre estomias para uso de } \\
\text { cuidadores e enfermeiros generalistas constitui uma estratégia de } \\
\text { educação à distância. } \\
\text { - Indicações de necessidades para pesquisas futuras: avaliação da } \\
\text { aplicação deste ensino online. }\end{array}$ \\
\hline 07 & Black PK & 2004 & $\begin{array}{l}\text { Psychological, } \\
\text { sexual and } \\
\text { cultural issues } \\
\text { for patients with } \\
\text { a stoma }\end{array}$ & $\begin{array}{l}\text { - Imagem corporal } \\
\text { - Aspectos psicológicos } \\
\text { - Sexualidade } \\
\text { - Considerações culturais }\end{array}$ & $\begin{array}{l}\text { - O ensino do paciente deve considerar os aspectos técnicos, além de } \\
\text { aspectos psicológicos, percepção da imagem corporal e sexualidade. } \\
\text { - O profissional enfermeiro deve atentar para aspectos culturais e não } \\
\text { julgamento do paciente, atuando com comunicação adequada para } \\
\text { tratamento efetivo e reabilitação do paciente. }\end{array}$ \\
\hline 22 & $\begin{array}{l}\text { Pereira, } \\
\text { Adriana } \\
\text { Pelegrini dos } \\
\text { Santos }\end{array}$ & 2006 & $\begin{array}{l}\text { Educação sexual } \\
\text { de grupos de } \\
\text { adultos } \\
\text { portadores de } \\
\text { estomas } \\
\text { intestinais } \\
\text { definitivos; } \\
\text { processo de } \\
\text { implantação e } \\
\text { implementação. }\end{array}$ & $\begin{array}{l}\text { - Troca de experiências } \\
\text { - Obtenção de conhecimento } \\
\text { - Cumplicidade / Companheirismo } \\
\text { - Aceitação da nova condição } \\
\text { - Atividade grupal / Grupo } \\
\text { Operativo }\end{array}$ & $\begin{array}{l}\text { - Os principais obstáculos apontados foram: a recusa do parceiro, } \\
\text { disfunção erétil, alteração da imagem e o próprio estoma. } \\
\text { - Os caminhos apontados para satisfação sexual forma: a troca do } \\
\text { parceiro, busca de profissionais especializados, criatividade no ato sexual } \\
\text { e alguns cuidados com dispositivo. } \\
\text { - A experiência de vida de cada integrante permitiu o desenvolvimento } \\
\text { da autonomia sexual e fez com que os portadores reconhecessem a } \\
\text { necessidade de mantê-la ou buscar auxílio, para o alcance do prazer, } \\
\text { satisfação e retorno à vida. }\end{array}$ \\
\hline
\end{tabular}


Estudos incluídos na categoria Complicações Ribeirão Preto - São Paulo, 2007.

\begin{tabular}{|c|c|c|c|c|c|}
\hline $\mathbf{N}^{\mathbf{0}}$ & AUTOR & ANO & TÍTULO & $\begin{array}{c}\text { ASPECTOS } \\
\text { ABORDADOS }\end{array}$ & CONCLUSÕES \\
\hline 08 & $\begin{array}{l}\text { Boyd K; } \\
\text { Thompson MJ; } \\
\text { Boyd-Carson W; } \\
\text { Trainor B }\end{array}$ & 2004 & $\begin{array}{l}\text { Use of convex } \\
\text { appliances }\end{array}$ & $\begin{array}{l}\text { - Avaliação de } \\
\text { enfermagem aos pacientes } \\
\text { que requerem produtos } \\
\text { convexos } \\
\text { - Indicações para uso de } \\
\text { produtos convexos e } \\
\text { respectivas definições }\end{array}$ & $\begin{array}{l}\text { - A convexidade tem um papel essencial no manejo das dificuldades come } \\
\text { stoma. Entretanto, deve ser usado apropriadamente e com seguimento e } \\
\text { avaliação de enfermagem, seguindo o protocolo de especialista clínico. }\end{array}$ \\
\hline 10 & $\begin{array}{l}\text { Boyd-Carsson W; } \\
\text { Thompson MJ; } \\
\text { Trainor B; Boyd K }\end{array}$ & 2004 & $\begin{array}{l}\text { Mucocutaneous } \\
\text { separation }\end{array}$ & $\begin{array}{l}\text { - Causas da separação } \\
\text { mucocutânea, sugestões de } \\
\text { ação e justificativa } \\
\text { - Tratamentos para } \\
\text { limpeza e cicatrização de } \\
\text { ferida }\end{array}$ & $\begin{array}{l}\text { - A cura precoce possibilitará maior adaptação à sua nova vida com estoma } \\
\text { e maior prática com cuidados da pele e troca, o que o fará retornar à } \\
\text { autoconfiança e auto-estima. }\end{array}$ \\
\hline 11 & $\begin{array}{l}\text { Rutledge M; } \\
\text { Thompson MJ; } \\
\text { Boyd-Carson W }\end{array}$ & 2003 & $\begin{array}{c}\text { Effective stoma } \\
\text { siting }\end{array}$ & $\begin{array}{l}\text { - Ações e razões para } \\
\text { assistência indidualizada ao } \\
\text { paciente: }\end{array}$ & - Demarcação do estoma é essencial na reabilitação dos pacientes. \\
\hline 12 & $\begin{array}{l}\text { Trainor B; } \\
\text { Thompson MJ; } \\
\text { Boyd-Carson W; } \\
\text { Boyd K }\end{array}$ & 2003 & $\begin{array}{l}\text { Changing na } \\
\text { appliance }\end{array}$ & $\begin{array}{l}\text { - Causas comuns de } \\
\text { problemas de pele } \\
\text { periestoma. } \\
\text { - Tipos de estoma, } \\
\text { aparência e funcionamento } \\
\text { normal. } \\
\text { - Procedimentos para troca } \\
\text { e adequação } \\
\text { dispositivos. }\end{array}$ & $\begin{array}{l}\text { - A proposta de protocolo fornece informações sobre aparência normal de } \\
\text { estoma, tamanho, características do efluente e descreve a técnica correta } \\
\text { para escolha, troca e aplicação de dispositivos. O protocolo também trata } \\
\text { das causas comuns de problemas de pele periestoma e as ações apropriadas } \\
\text { são destacadas. }\end{array}$ \\
\hline
\end{tabular}




\section{ANEXOS}

\section{Instrumento para Coleta de Dados Bibliográficos}

1) Dados referentes ao pesquisador:

$1^{\circ}$ Autor

Nome:

Profissão:

( ) Enfermeiro

( ) Médico Especialidade:

( )Psicólogo

( )Outros:

Titulação:

( )pós-doutor ( )doutor ( )mestre

( )especialista ( )graduado

( )discente ano

Local de atuação:

$2^{\circ}$ Autor

Nome:

Profissão:

( ) Enfermeiro

( ) Médico Especialidade:

( )Psicólogo

( ) Outros:

Titulação:

( )pós-doutor ( )doutor ( )mestre

( )especialista ( )graduado

( )discente ano

Local de atuação: 
2) Dados referentes à publicação:
( )tese / dissertação
( )artigo
( ) )livro

Título:

Ano:

Volume:

$\mathrm{N}^{\mathrm{o}}$ :

Páginas:

País de origem:

Fonte (revista):

Idioma:

3) Base de Dados:
( ) Lilacs
( )Medline
( )Dedalus
( )BDENF
( )Outros:

4) Acesso à pesquisa na íntegra:

( ) Biblioteca da Universidade de São Paulo

( ) Biblioteca da E.E.R.P

( ) COMUT

( ) Bireme

5) Objetivo do Estudo: 
6) População:

7) Amostra:

8) Tipo de desenho do estudo:

9) Aspectos abordados pelo autor:

Categorização / Tema:

10) Resultados / Conclusões: 